\title{
Immunohistochemical and ultrastructural characterization of the initial post-hatching development of bovine embryos
}

\author{
P. Maddox-Hyttel ${ }^{1}$, N. I. Alexopoulos ${ }^{2}$, G. Vajta ${ }^{3}$, I. Lewis ${ }^{2}$, P. Rogers ${ }^{4}$, L. Cann ${ }^{4}$, \\ H. Callesen ${ }^{3}$, P. Tveden-Nyborg ${ }^{1}$ and A. Trounson ${ }^{2}$ \\ ${ }^{1}$ Department of Anatomy and Physiology, Royal Veterinary and Agricultural University, \\ Groennegaardsvej 7, DK-1870 Frederiksberg C, Denmark; ${ }^{2}$ Monash Institute of Reproduction and \\ Development, Monash Medical Centre, 246 Clayton Road, Clayton, Victoria 3168, Australia; \\ ${ }^{3}$ Department of Animal Breeding and Genetics, Danish Institute of Agricultural Sciences, PO Box 50, \\ DK-8830 Tjele, Denmark; and ${ }^{4}$ Monash University, Department of Obstetrics and Gynaecology, Monash \\ Medical Centre, 246 Clayton Road, Clayton, Victoria 3168, Australia
}

The problems of sustaining placenta formation in embryos produced by nuclear transfer have emphasized the need for basic knowledge about epiblast formation and gastrulation in bovine embryos. The aims of this study were to define stages of bovine post-hatching embryonic development and to analyse functional mechanisms of germ-layer formation. Embryos developed in vivo were collected after slaughter from superovulated cows on days 9, 11, 14 and 21 after insemination and processed for transmission electron microscopy $(n=26)$ or immunohistochemistry $(n=27)$ for potential germ-layer characterization (cytokeratin 8 for potential ectoderm; alpha-1-fetoprotein for potential endoderm; and vimentin for potential mesoderm). On day 9, the embryos were devoid of zona pellucida and presented a well-defined inner cell mass (ICM), which was covered by a thin layer of trophoblast cells (the Rauber's layer). Formation of the hypoblast from the inside of the ICM was ongoing. On day 11 , the Rauber's layer was focally interrupted and adjacent underlying ICM cells formed tight junctions. The hypoblast, which formed a thin confluent cell layer, was separated from the ICM and the trophoblast by intercellular matrix. The embryos were ovoid to tubular and displayed a confluent hypoblast on day 14 . The epiblast was inserted into the trophoblast epithelium and tight junctions and desmosomes were present between adjacent epiblast cells as well as between peripheral epiblast and trophoblast cells. In some embryos, the epiblast was more or less covered by foldings of trophoblast in the process of forming the amniotic cavity. Cytokeratin
8 was localized to the trophoblast and the hypoblast underlying the epiblast; alpha-1-fetoprotein was localized to most hypoblast cells underlying the trophoblast; and vimentin was localized to most epiblast cells. On day 21, the smallest embryos displayed a primitive streak and formation of the neural groove, whereas the largest embryos presented a neural tube, up to 14 somites and allantois development. These embryos depicted the gradual formation of the endoderm, mesoderm and ectoderm as well as differentiation of paraxial, intermediate and lateral plate mesoderm. Cytokeratin 8 was localized to the trophoblast, the hypoblast and the surface and neural ectoderm; and alpha-1-fetoprotein was localized to the hypoblast, but not the definitive endoderm, the intensity increasing with development. Vimentin was initially localized to some, but not all, cells positioned particularly in the ventral region of the primitive streak, to presumptive definitive endoderm cells inserted into the hypoblast, and to mesoderm. In conclusion, within 2 weeks of hatching, bovine embryos complete formation of the hypoblast and the epiblast, establishment of the amniotic cavity, ingression of epiblast cells for primitive streak formation, involution of cells through the node and the streak for endoderm and mesoderm fomation, neurulation and differentiation of the mesoderm. The recruitment of cells from the epiblast to form the primitive streak as well as the endoderm and mesoderm is associated with expression of the intermediate filament vimentin.

\section{Introduction}

Procedures such as in vitro embryo production or, in particular, reconstruction of embryos by nuclear

Email: poh@kvl.dk transfer hamper the developmental potential of the resulting embryos. Thus, it has been demonstrated that bovine blastocysts produced in vitro display abnormal expression of a number of genes that are of importance for embryonic development (Niemann and Wrenzycki, 2000) as well as higher frequencies of chromosomal 
aberrations (Viuff et al., 1999, 2000, 2001) and apoptosis (Gjørret et al., 2001). Nuclear transfer embryos display even more pronounced deviations in gene expression (Daniels et al., 2000; Hyttel et al., 2001; Wrenzycki et al., 2001; Laurincik et al., 2002; Niemann et al., 2002) as well as increased occurrence of chromosomal abnormalities (Booth et al., 2002) and apoptosis (Gjørret et al., 2002).

Aberrant gene expression patterns as well as the increased occurrence of chromosomal aberrations and apoptosis may be causally involved in the loss of embryos and fetuses throughout pregnancy, in particular after nuclear transfer (Hill et al., 1999; Wells et al., 1999; Heyman et al., 2002). This loss is apparently related to compromised placental function after both in vitro embryo production (Bertolini and Anderson, 2002) and nuclear transfer (Hill et al., 2000; De Sousa et al., 2001; Heyman et al., 2002).

Large domestic mammals have a chorio-allantoic placenta, the development of which is dependent on proper formation and vascularization of the allantois. The allantois is formed as an endoderm-derived diverticulum from the hindgut and its vascularization develops from the splanchnic mesoderm. Thus, the establishment and function of the chorio-allantoic placenta requires proper formation of the germ layers, that is, the endoderm, mesoderm and ectoderm, during the process of gastrulation. Some features of gastrulation in the bovine embryo have been reported (Winters et al., 1942; Chang, 1952; Greenstein and Foley, 1958; Fléchon, 1978; Betteridge et al., 1980; Gustafsson and Ploen, 1986; Hue et al., 2001) and reviewed by Betteridge and Fléchon (1988) and Guillomot (1995). After shedding the zona pellucida, which occurs most commonly on days $8-10$ after fertilization in cattle, the embryo is transformed from a spherical to an ovoid form; a process that marks the onset of the more obvious elongation initiated between days 12 and 14 (Betteridge et al., 1980). By day 8 , the first hypoblast cells (sometimes referred to as the primitive endoderm), are formed from the inner cell mass (ICM), and by day 10 they have established a confluent hypoblast lining the inside of the trophoblast. At about day 12, the ICM, now referred to as the epiblast, displaces the thin overlying trophoblast lining, that is, the Rauber's layer (Fléchon, 1978), and establishes the embryonic disc. By day 14 (Winters et al., 1942) or day 16 (Greenstein and Foley, 1958) the mesoderm formation is initiated, and by day 20 the allantois buds into the extra-embryonic coelom (Fléchon, 1978).

From the data outlined above it is clear that there has been only limited recent investigation of bovine post-hatching embryonic development. Hence, the aim of the present study was to characterize for the first time the initial post-hatching development in bovine embryos by (1) transmission electron microscopy (TEM) to elucidate the subcellular mechanisms of establishment of the embryonic disc; and (2) alkaline phosphatase staining and immunohistochemistry using markers for the three germ layers to elucidate potential pluripotency and allocation of cells to the germ layers, repectively.

\section{Materials and Methods}

Superovulation, collection, dissection and fixation of embryos

For collection of embryos 9 and 11 days after fertilization (performed at the Danish Institute of Agricultural Sciences, Tjele, Denmark), six HolsteinFriesian heifers were superovulated. On the morning of treatment day 0 , exogenous progesterone and oestradiol were administered per vaginam (controlled internal drug releasing device (CIDR) with capsule; Vetcare Oy, Salo). The heifers received an injection of $500 \mathrm{mg}$ cloprostenol (Estrumat ${ }^{\circledR}$ Vet., Schering-Plough, Farum) i.m. and the CIDRs were removed on the morning of treatment day 8 . Standing oestrus was observed in all heifers on treatment day 10 . From the morning of treatment day 20, the heifers received eight i.m. injections of FSH (Folltropin; Vetrepharm, Belleville) in decreasing doses every $12 \mathrm{~h}$ (total FSH dose of $200 \mathrm{mg}$ ). A dose of $375 \mathrm{mg}$ cloprostenol was given in the morning and again in the afternoon of treatment day 22. The heifers were inseminated with one straw containing approximately $20 \times 10^{6}$ spermatozoa at $12 \mathrm{~h}$ and again at $24 \mathrm{~h}$ after standing oestrus was observed, which was approximately $48 \mathrm{~h}$ after the last cloprostenol injection in all heifers. The day of the first insemination was defined as the day of fertilization (day 0 of gestation). The heifers were slaughtered on day 9 of gestation $(n=3)$ or $11(n=3)$ and the genital organs were taken to the laboratory at room temperature within $30 \mathrm{~min}$. Subsequently, each uterine horn was flushed with PBS with $5 \%$ bovine serum (Danish Veterinary Institute, Frederiksberg) by a bovine embryo flushing catheter placed through an incision in the uterine horn near the junction to the uterine body.

For collection of embryos on days 14 and 21 of gestation (performed at Monash University, Melbourne, Australia) six Holstein-Friesian heifers were superovulated. On treatment day 0 , the animals received an injection of $500 \mathrm{mg}$ cloprostenol sodium (Estrumate, Jurox) i.m. and another on treatment day 11. On treatment day 17 , exogenous progesterone was administered per vaginam (CIDR; Genetics Australia, Bacchus Marsh). On the morning of treatment day 20 , donors received $5 \mathrm{mg}$ oestradiol i.m. From the afternoon of treatment day 23, donors received eight i.m. injections of FSH (Ovagen, ICP, Auckland) in decreasing doses every $12 \mathrm{~h}$ (total FSH dose of $15-18 \mathrm{mg}$, depending on parity and previous superovulation history). A dose of $500 \mathrm{mg}$ cloprostenol was adminstered in the afternoon of treatment day 25 and in the morning of day 26, and CIDRs were removed in the afternoon of day 26 . Donors were inseminated with one straw containing approximately $20 \times 10^{6}$ spermatozoa, 
12 and $24 \mathrm{~h}$ after standing oestrus (24-36 h after CIDR removal). The day of the first insemination was defined as the day of fertilization (day 0 of gestation). Four of the best responding animals (according to rectal palpation) were slaughtered on days $14(n=2)$ and $21(n=2)$ of gestation and the genital organs were taken to the laboratory at room temperature within $1 \mathrm{~h}$. Subsequently, each uterine horn was flushed with PBS with $5 \%$ fetal calf serum by an equine embryo flushing catheter placed through an incision in the uterine horn near the junction to the body of the uterus.

Embryos were identified in the flushing medium by stereomicroscopy and fixed (see below). On days 9, 11 and 14 of gestation, the complete embryo was fixed whereas on day 21 of gestation, the embryo proper was isolated from the trophoblast and yolk sac (hypoblast) and transferred to the fixatives. The specimens were fixed for either TEM (characterization of embryonic disc formation) or alkaline phosphatase staining and immunohistochemistry (characterization of pluripotency and allocation of cells to germ layers, repectively). Specimens for TEM were fixed for $1 \mathrm{~h}$ at $4{ }^{\circ} \mathrm{C}$ in $3 \%$ glutaraldehyde in 0.1 mol sodium cacodylate $\mathrm{I}^{-1}$ buffer (day 9: $n=2$; day $11: n=2$; day $14: n=13$; day 21 : $n=9$ ) and stored in fresh 0.1 mol sodium cacodylate $\mathrm{I}^{-1}$ buffer at $4^{\circ} \mathrm{C}$ until dehydration and embedding a few days later. Specimens for immunocytochemistry and alkaline phosphatase staining were fixed in $4 \%$ paraformaldehyde in $0.1 \mathrm{~mol} \mathrm{PBS} \mathrm{I}^{-1}$ for immunohistochemistry (day 14: $n=16$; day $21: n=11$ ) and stored in fresh $0.1 \mathrm{~mol}$ PBS $\mathrm{I}^{-1}$ at $4^{\circ} \mathrm{C}$ until dehydration and embedding a few days later.

Tissue processing, immunohistochemistry, alkaline phosphatase staining and microscopy

Specimens fixed for immunohistochemistry were dehydrated and embedded in paraffin wax whereas those for TEM were dehydrated and embedded in Epon. Embryos at days 9 and 11 of gestation were completely cut into serial sections (paraffin wax: $5 \mu \mathrm{m}$ sections; Epon: $2 \mu \mathrm{m}$ sections), whereas 100-300 representative sections were cut from embryos at days 14 and 21 of gestation. Selected paraffin wax sections were stained with haematoxylin-eosin for orientation purposes, whereas all Epon sections were stained with $1 \%(\mathrm{w} / \mathrm{v})$ basic Toluidine blue. All stained sections were analysed by bright field light microscopy. The remaining paraffin wax sections were selected for immunohistochemistry, whereas selected Epon sections from embryos on days 9, 11 and 14 were re-embedded for ultrathin sectioning (Hyttel and Madsen, 1987). The ultrathin sections were stained with uranyl acetate and lead citrate and examined on a Jeol 1200 EX transmission electron microscope.

For immunohistochemical characterization, consecutive paraffin wax sections were labelled with three antibodies used as potential markers for the germ layers as well as for alkaline phosphatase staining (day 14 of gestation only). The three primary antibodies used were murine monoclonal anti-cytokeratin 8 (Becton Dickinson, San Jose, CA) for potential ectoderm labelling (Page, 1989), rabbit polyclonal anti-human alpha-1fetoprotein (Dako, Glostrup) for potential endoderm (Dziadek and Adamson, 1978), and monoclonal mouse anti-human vimentin (Zymed, San Francisco, CA) for potential mesoderm (Jackson et al., 1981; Franke et al., 1982; Page, 1989). For labelling, $5 \mu \mathrm{m}$ sections were collected on APES coated slides (slides were briefly dipped in $2.5 \%$ 3-aminopropyltriethoxysilane in methanol and allowed to air dry before use) and adhered to the slide with an overnight incubation at $37^{\circ} \mathrm{C}$. Subsequently, the sections were de-waxed and rehydrated. Antigen retrieval by microwave treatment in 0.01 mol sodium citrate $\mathrm{I}^{-1}$ buffer ( $\mathrm{pH} \mathrm{6.0)}$ for $15 \mathrm{~min}$ was used for detection of alpha-1-fetoprotein and vimentin. Subsequently, endogenous peroxidase activity was blocked with $3 \%(\mathrm{v} / \mathrm{v}) \mathrm{H}_{2} \mathrm{O}_{2}$ in methanol and non-specific binding of antibodies was blocked with protein blocking agent (Immunon, Pittsburgh, PA). Incubation with the primary antibodies (cytokeratin 8: 1:1; alpha-1-fetoprotein: 1:5000; vimentin: 1:500) in $1 \%$ BSA in PBS was performed overnight at $4^{\circ} \mathrm{C}$. Negative control slides were incubated with identical concentrations of non-immune sera (cytokeratin: mouse IgG2A (Chemicon, Temecula, CA); alpha-1-fetoprotein: rabbit IgG (Sigma, St Louis, MO); vimentin: mouse IgG1 (Chemicon)). The primary antibodies were visualized by Dako LSAB + kit and the sections counterstained with Mayer's haematoxylin and mounted in Dako permanent aqueous mountant.

Alkaline phosphatase activity was visualized by means of a kit from Sigma (procedure no. 68). The same types of section as mentioned above were incubated according to the protocol provided by the manufacturer for $30 \mathrm{~min}$ to $4 \mathrm{~h}$. Positive staining was obtained after $30 \mathrm{~min}$ incubation. Negative control specimens were incubated in a similar way with 5 mmol levamisol $\mathrm{I}^{-1}$ (Sigma) added to the substrate.

\section{Results}

The following chronology refers to days of gestation.

\section{General structure and ultrastructure on day 9}

Both embryos were devoid of zona pellucida. The trophoblast cells were cuboidal except over the welldefined ICM where they formed a thin layer, that is, the Rauber's layer (Fig. 1a,b). On the internal side of the ICM and trophoblast, scattered individual hypoblast cells were seen (Fig. 1a). Focal contact areas were observed between the plasma membranes of the hypoblast and the trophoblast cells (Fig. 1c). Adjacent trophoblast cells 

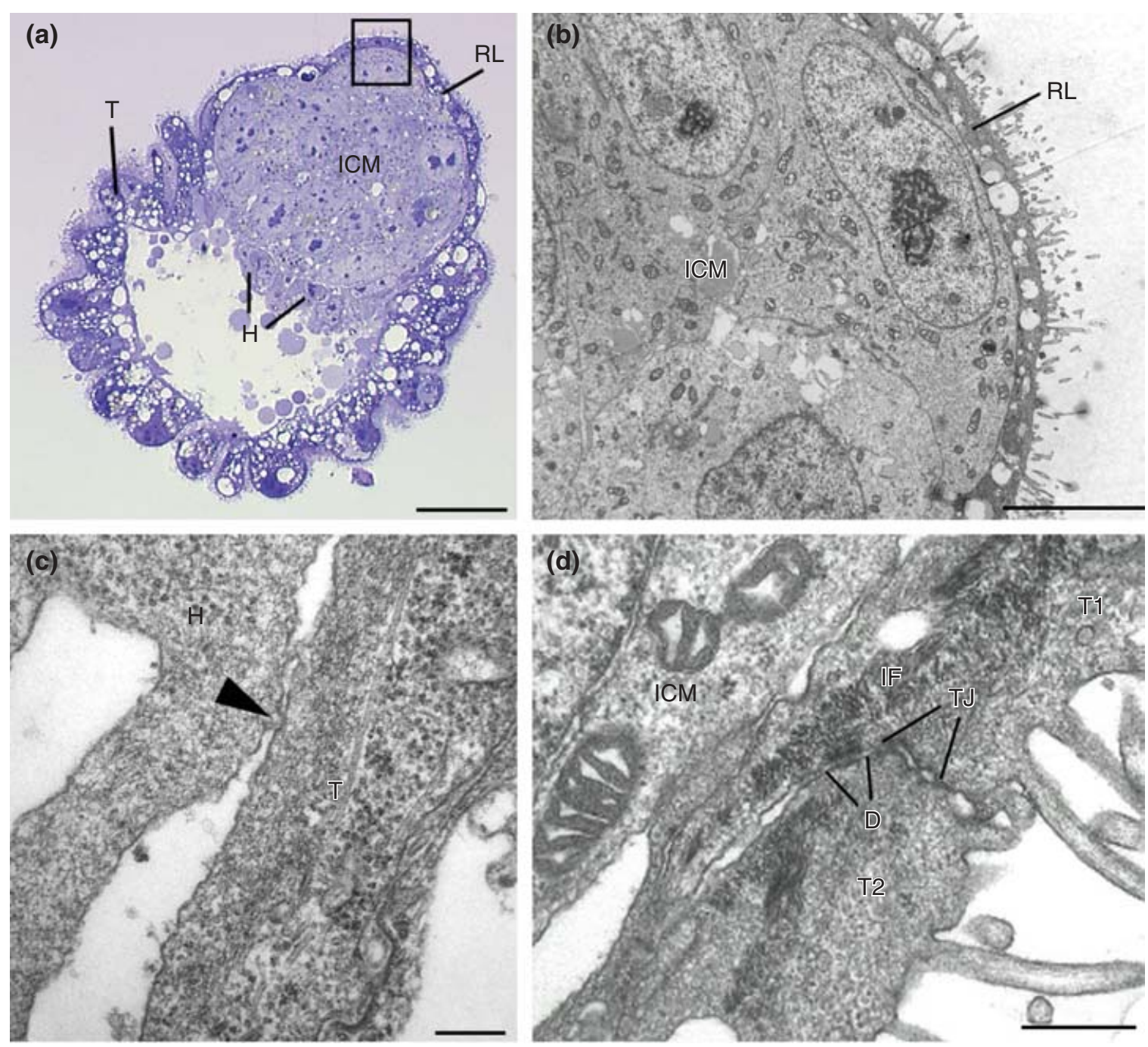

Fig. 1. Day 9 bovine embryo. (a) Light micrograph showing the cuboidal trophoblast (T) cells and the well-defined inner cell mass (ICM). Note the thin trophoblast covering the ICM, that is, the Rauber's Layer (RL) and the hypoblast (H) scattered on the internal surface of the ICM. (b) Transmission electron micrograph (TEM) of the boxed region in (a) showing the RL covering the ICM. (c) TEM showing a focal contact (arrowhead) between a trophoblast and a hypoblast cell. (d) TEM showing tight junctions (TJ) and desmosomes (D), connected to intermediate filaments (IF), between two trophoblast cells (T1 and T2) in the RL covering the ICM. Scale bars represent (a) $20 \mu \mathrm{m}$, (b) $5 \mu \mathrm{m}$, (c) $200 \mathrm{~nm}$ and (d) $500 \mathrm{~nm}$.

were connected by tight junctions and desmosomes, also in the Rauber's layer (Fig. 1d). The outer cells of the ICM, underlying the Rauber's layer, were closely apposed and their plasma membranes formed interdigitations, whereas the cells of the internal portion of the ICM were more loosely attached to each other. The most conspicuous organelles of the cells of the ICM were mitochondria, polyribosomes, rough endoplasmic reticulum and Golgi complexes.

\section{General structure and ultrastructure on day 11}

The trophoblast was cuboidal to columnar except over the well-defined ICM where the Rauber's layer was very thin (Fig. 2a). In one embryo, a focal interruption of this layer was formed by cell disintegration (Fig. 2b). At all other locations, adjacent trophoblast cells were connected by tight junctions and desmosomes. The outer cells of the ICM were closely apposed and initial formation of tight junctions between them was noted (Fig. 2C). A very thin but confluent hypoblast lined the ICM and the trophoblast internally (Fig. 2a). In one embryo, extracellular matrix was observed between the hypoblast and the ICM. In the other embryo, this matrix also extended between the hypoblast and trophoblast (Fig. 2d). Adjacent hypoblast cells were connected by tight junctions, some of which were in the initial process of being formed. The most conspicuous organelles of 

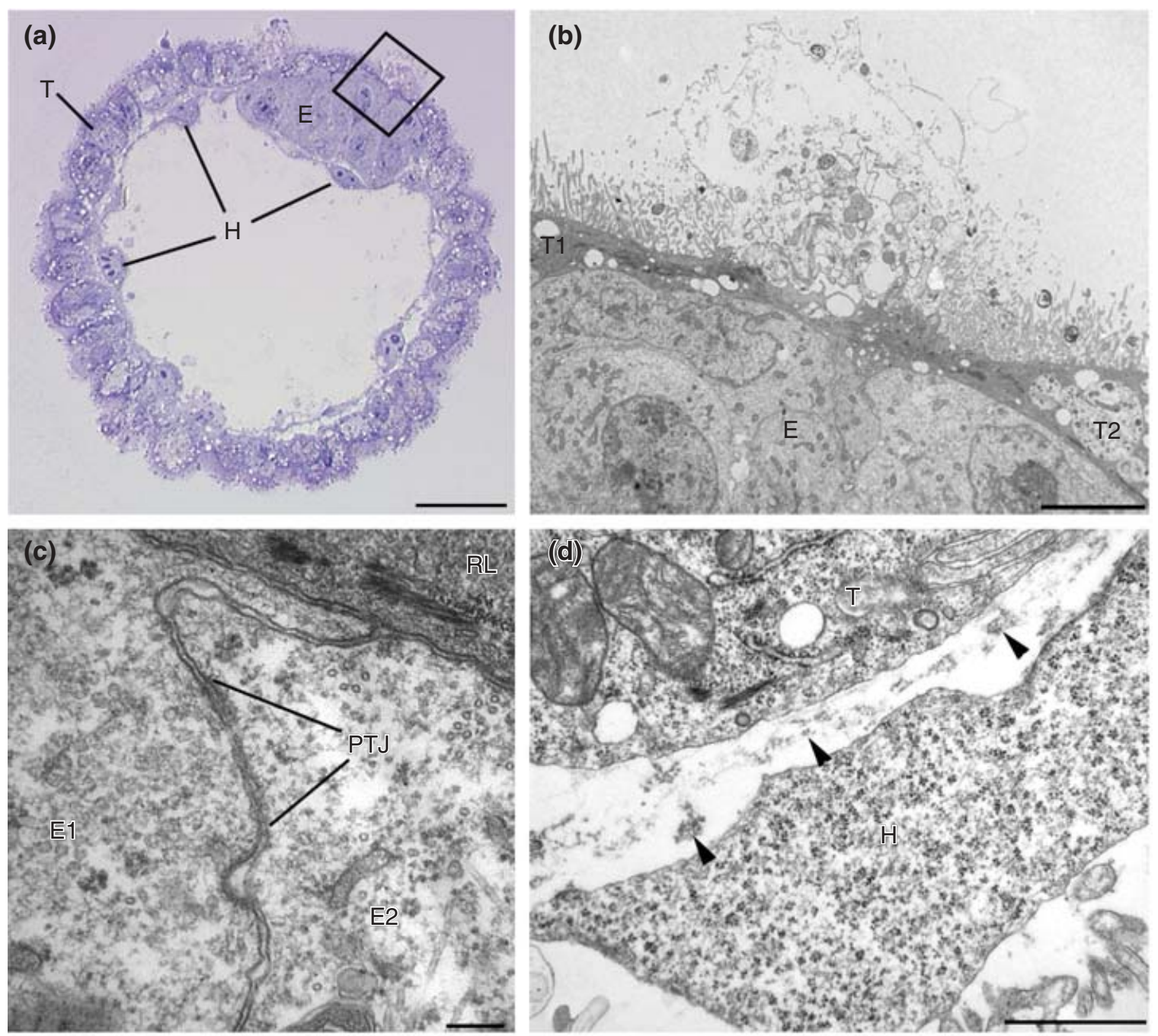

Fig. 2. Day 11 bovine embryo. (a) Light micrograph showing the cuboidal trophoblast cells (T) and the well-defined epiblast (E). Note that the hypoblast $(\mathrm{H})$ is complete and that the Rauber's Layer (RL) is disintegrating (boxed area). (b) Transmission electron micrograph (TEM) of the boxed area from (a). Note the disintegration of the RL between two trophoblast cells (T1 and T2) covering the epiblast. (c) TEM showing the formation of presumptive tight junctions (PTJ) between two epiblast cells (E1 and E2) covered by the RL. (d) TEM showing extracellular matrix (arrowheads) between a trophoblast and a hypoblast cell. Scale bars represent (a) $20 \mu \mathrm{m}$, (b) $5 \mu \mathrm{m}$, (c) $200 \mathrm{~nm}$ and (d) $1 \mu \mathrm{m}$.

the cells of the ICM were mitochondria and polyribosomes.

\section{General structure and ultrastructure on day 14}

The embryos ranged from ovoid to, in most cases, tubular in shape and the total length varied from $0.50 \mathrm{~mm}$ to $19.00 \mathrm{~mm}$ with a mean of $5.23 \mathrm{~mm}$. In 25 of 28 embryos, an embryonic disc was identified. In the smallest ovoid embryos (up to about $1.50 \mathrm{~mm}$ ), it was not possible to delineate the embryonic disc exactly (Fig. $3 a)$. In the remaining embryos, the disc formed a distinct bulge and ranged from $0.10 \mathrm{~mm}$ to $0.44 \mathrm{~mm}$ in length (Fig. 4a).
On sections, the epiblast, defining the embryonic disc, was clearly discernible and formed a continuous epithelium with the trophoblast (Figs $3 \mathrm{~b}$ and $4 \mathrm{~b}$ ). Both cellular compartments were internally lined by the continuous hypoblast which was squamous under the trophoblast and cuboidal to columnar under the epiblast. A basal lamina was formed between the trophoblast or epiblast and the hypoblast (Fig. 4c). Adjacent epiblast cells were connected by tight junctions and desmosomes (Fig. 4d), as were the most peripheral epiblast cells and the adjacent trophoblast cells (Fig. 4e). The most conspicuous organelles of the epiblast cells were mitochondria and polyribosomes.

On one occasion, a semicircular condensation of cells was seen between the epiblast and the hypoblast 

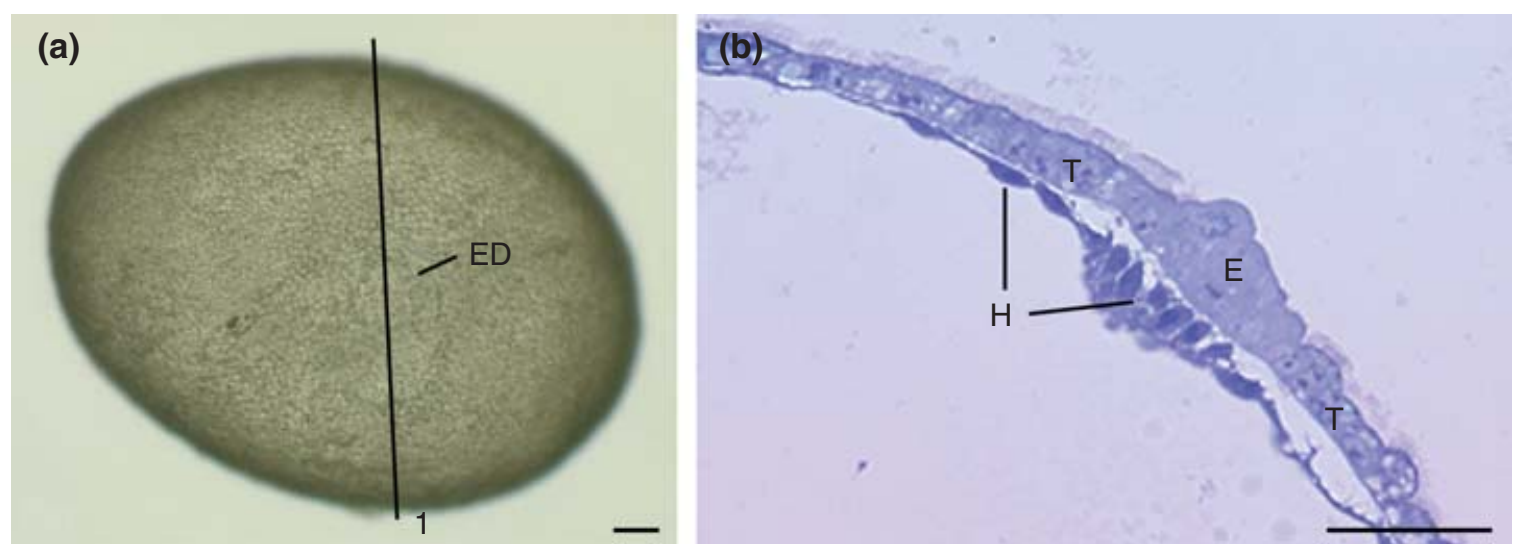

Fig. 3. Day 14 bovine embryo. (a) An ovoid embryo with a poorly delineated embryonic disc (ED) as seen under a stereomicroscope. (b) Light micrograph of a section oriented as line 1 in (a). Note the trophoblast (T), covered with abundant microvilli, the epiblast (E), and the hypoblast (H). Scale bars represent (a) $0.1 \mathrm{~mm}$ and (b) $50 \mu \mathrm{m}$.

in one pole of the embryonic disc (Fig. 5a-c). These cells, which are presumptive precursors for primitive streak formation and thus for endoderm and mesoderm, displayed extensions towards the basal lamina lining the epiblast internally and were rich in presumptive intermediate filaments (Fig. $5 \mathrm{~d}$ ).

In a few embryos, the initial formation of the amnion was also observed. Amniotic folds were formed in the trophoblast adjacent to the epiblast (Fig. 6a). The hypoblast was not included in these folds (Fig. 6b).

In 4 of the 28 embryos, presumptive signs of early embryonic mortality were noticed. Two embryos were contracted and no embryonic disc could be localized. Another embryo displayed an epiblast with several presumptive apoptotic cells (Fig. 7a,b). The hypoblast of this embryo was attached only to the epiblast; it had loosened from most of the trophoblast. The last embryo displayed trophoblast proliferation and a degenerative ICM that had never created an epiblast.

\section{Immunohistochemical labelling and alkaline phosphatase staining on day 14}

A schematic overview of the immunohistochemical staining is presented (Fig. 8). Strong labelling for cytokeratin 8 was seen in the trophoblast, and the cuboidal to columnar hypoblast cells internal to the epiblast displayed moderate labelling (Fig. 9a,b). Labelling for alpha-1-fetoprotein was found in most hypoblast cells (Fig. 10a,b). A focal cytoplasmic labelling for vimentin was found in most epiblast cells (Fig. 11a,b). Alkaline phosphatase staining was not observed in the epiblast whereas the trophoblast was clearly stained and the hypoblast was moderately stained (Fig. 12a,b).

\section{General structure on day 21}

In all cases, the trophoblast and the yolk sac were removed during the initial processing, allowing for
Table 1. Relationship between embryo length, numbers of somite pairs and width of the allantois in day 21 bovine embryos

\begin{tabular}{lll}
\hline $\begin{array}{l}\text { Length of } \\
\text { embryo }(\mathrm{mm})\end{array}$ & $\begin{array}{l}\text { Number of } \\
\text { somite pairs }\end{array}$ & $\begin{array}{l}\text { Width of } \\
\text { allantois }(\mathrm{mm})\end{array}$ \\
\hline 3.14 & 2 & Not visible \\
3.77 & 9 & Not visible \\
3.92 & 8 & 1.15 \\
3.92 & 12 & 2.00 \\
4.60 & 10 & 2.20 \\
5.40 & 14 & 2.71 \\
5.79 & 14 & 4.41 \\
\hline
\end{tabular}

fixation of the embryo proper, enclosed by the amnion, with the allantoic bud, if present. The total length of the conceptuses was up to about $30 \mathrm{~cm}$, whereas the length of the embryo proper ranged from $0.78 \mathrm{~mm}$ to $5.79 \mathrm{~mm}$ with an average of $2.86 \mathrm{~mm}$. The smallest embryo $(0.78 \mathrm{~mm})$ presented a primitive streak extending far towards the cranial pole (Fig. 13a), but there was no neural groove development. A well-defined mass of endoderm and mesoderm precursor cells extended cranially from the caudal pole between the epiblast and the hypoblast (Fig. 13b). At the edge of the embryonic disc, the mesoderm split into somatic mesoderm, delineating the trophoblast lining of the amniotic cavity, and splanchnic mesoderm lining the hypoblast. Between the mesoderm layers, the intra- and extraembryonic coelom was established.

Embryos ranging from $1.13 \mathrm{~mm}$ to $3.00 \mathrm{~mm}$ in length displayed gradual formation of the neural plate, the neural groove and the neural tube (Figs 14a,b and $15 \mathrm{a}, \mathrm{b})$. In embryos $>5.40 \mathrm{~mm}$, the caudal neuropore was closed, but the rostral neuropore remained open in all embryos. Formation of the initial somites was observed in a $3.14 \mathrm{~mm}$ embryo. In longer embryos there was a clear relation between the number of somite pairs and the embryo length (Table 1). In these embryos, the 

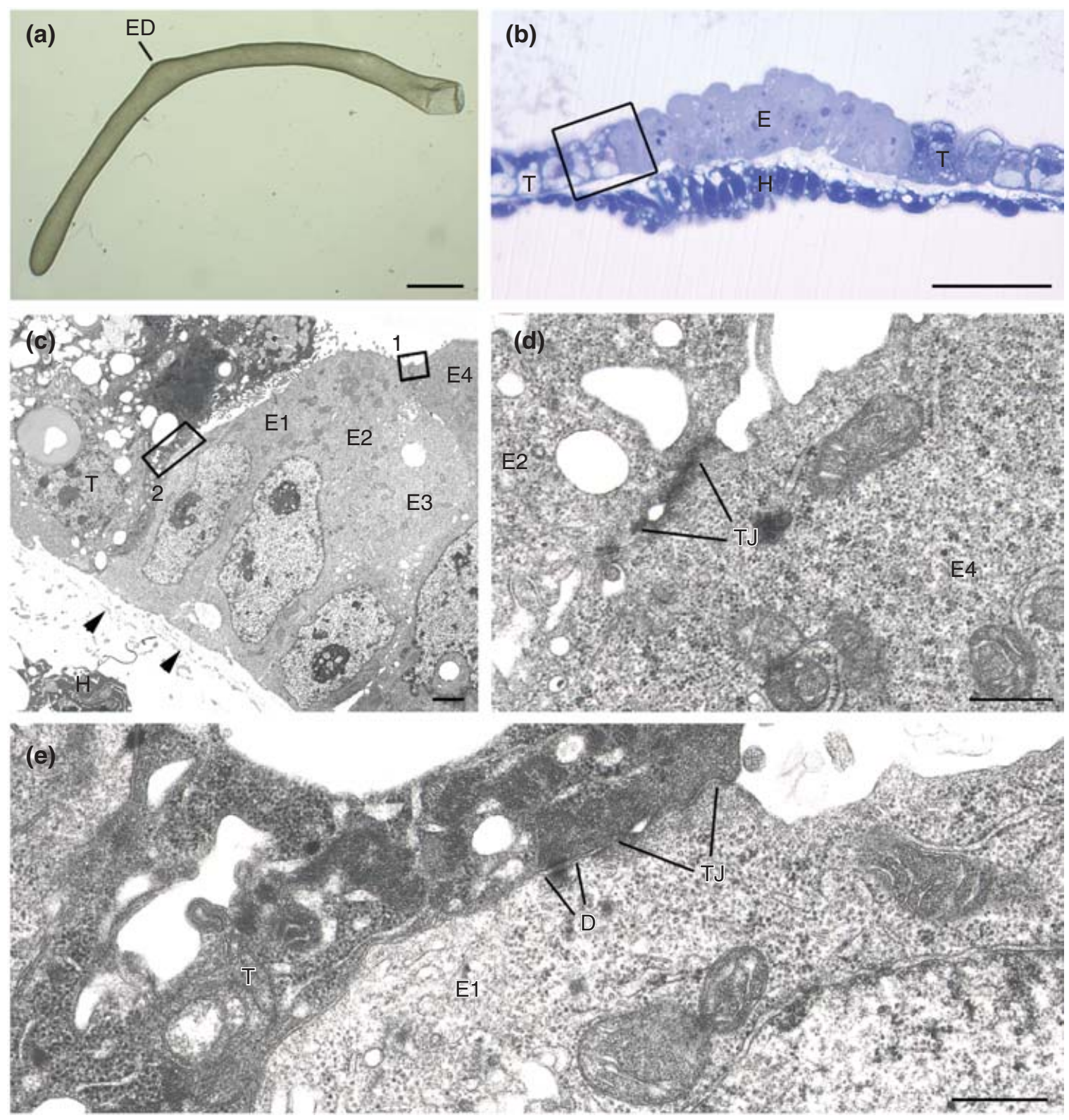

Fig. 4. Day 14 bovine embryo. (a) A tubular embryo with an embryonic disc (ED) as seen under a stereomicroscope. (b) Light micrograph showing a longitudinal section through the embryonic disc displaying trophoblast (T), epiblast (E) and hypoblast (H). (c) Transmission electron micrograph (TEM) of the boxed area in (b) showing the sequence of a trophoblast and four epiblast cells (E1, E2, E3 and E4). Note the basal lamina (arrowheads) between the trophoblast or epiblast and the underlying hypoblast. (d) TEM of boxed area 1 in (c) showing tight junctions (TJ) between two adjacent epiblast cells (E2 and E4). (e) TEM of boxed area 2 in (c) showing tight junctions and a desmosome (D) between a trophoblast and an epiblast cell (E1). Scale bars represent (a) $1 \mathrm{~mm}$, (b) $50 \mu \mathrm{m}$, (c) $2 \mu \mathrm{m}$, (d) $0.5 \mu \mathrm{m}$ and (e) $500 \mathrm{~nm}$.

mesoderm had differentiated into paraxial mesoderm forming the somites, intermediate mesoderm and somatic and splanchnic mesoderm.

The early development of the allantois was observed in a $3.92 \mathrm{~mm}$ embryo in which the T-shaped allantoic sac measured $1.1 \mathrm{~mm}$ in width. In longer embryos, there was a clear relationship between the allantois width and the embryo length (Table 1, Fig. 16).

\section{Immunohistochemical labelling on day 21}

A schematic overview of the immunohistochemical staining is presented (Fig. 17). In embryos at the primitive streak stage, weak labelling for cytokeratin 8 was seen in the trophoblast lining the inside of the amniotic cavity and in the hypoblast, but not in the definitive endoderm, which was inserted into the upper 

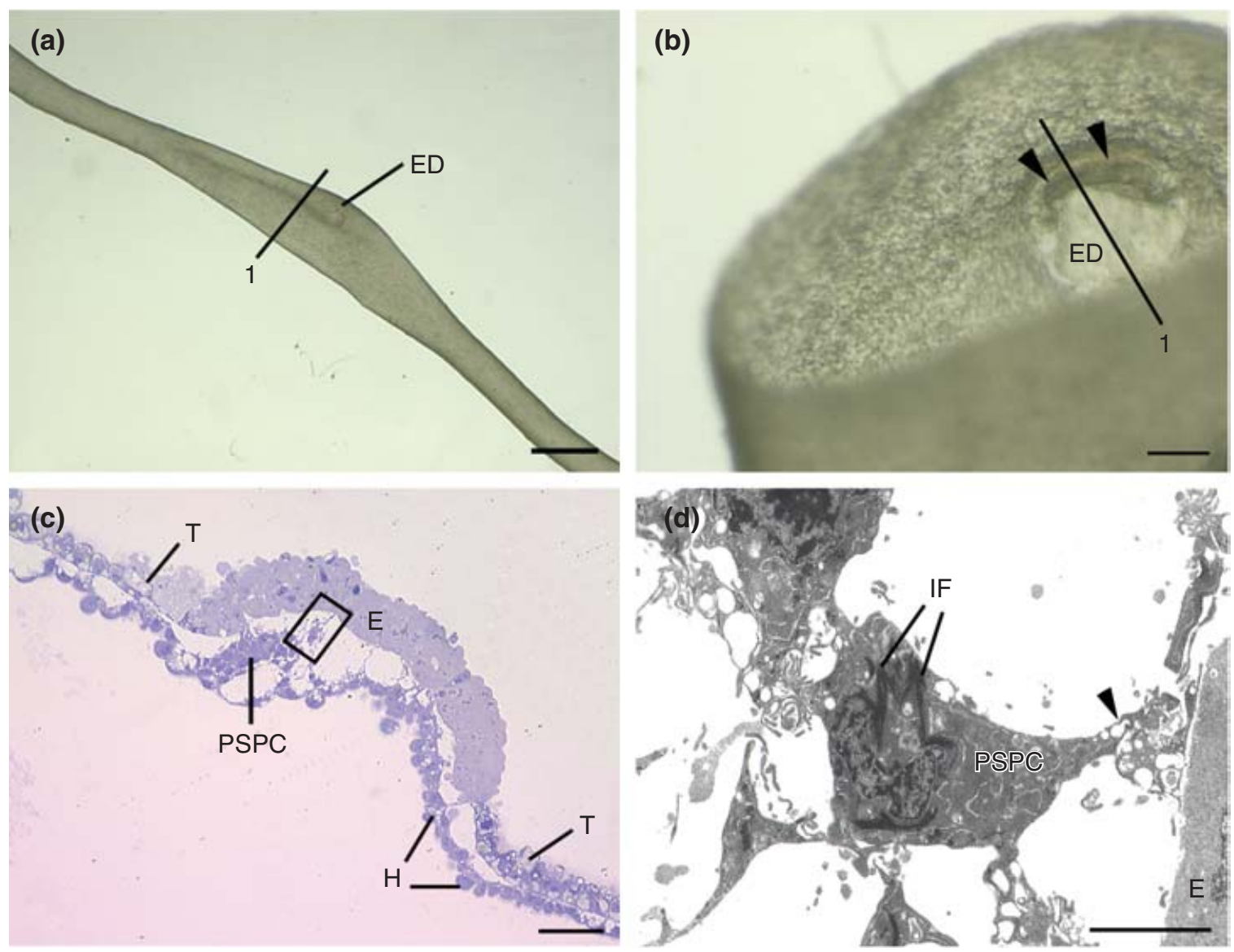

Fig. 5. Day 14 bovine embryo. (a) A tubular embryo with an embryonic disc (ED) as seen under a stereomicroscope. (b) An internal view of the embryo after transection along line 1 in (a) as seen through a stereomicroscope. Note the embryonic disc and the semicircular condensation of cells (arrowheads) at one pole of the embryonic disc. (c) Light micrograph of a section oriented as line 1 in (b). Note the trophoblast $(\mathrm{T})$, epiblast $(\mathrm{E})$, hypoblast $(\mathrm{H})$ and the accumulation of cells that are presumptive precursors for the primitive streak (PSPC). (d) Transmission electron micrograph of the boxed area in (c). Note the PSPC presenting intermediate filament bundles (IF) and an extension (arrowhead) towards the epiblast. Scale bars represent (a) $1 \mathrm{~mm}$, (b) $0.1 \mathrm{~mm}$, (c) $50 \mu \mathrm{m}$ and (d) $5 \mu \mathrm{m}$.
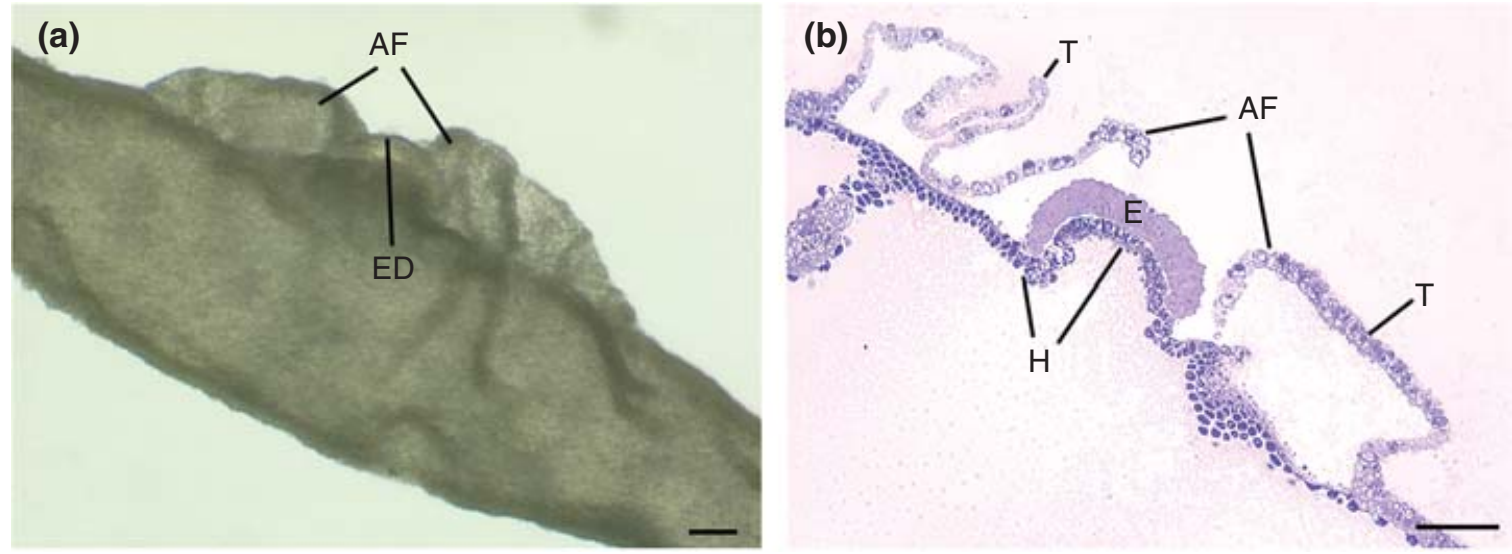

Fig. 6. Day 14 bovine embryo. (a) Amniotic foldings (AF) at each pole of the embryonic disc (ED) as seen under a stereomicroscope. (b) Light micrograph showing the AF, consisting of trophoblast $(\mathrm{T})$, epiblast $(\mathrm{E})$ and hypoblast $(\mathrm{H})$. Owing to an artefact, the trophoblast is no longer connected to the epiblast. Scale bars represent (a) $0.1 \mathrm{~mm}$ and (b) $100 \mu \mathrm{m}$. 

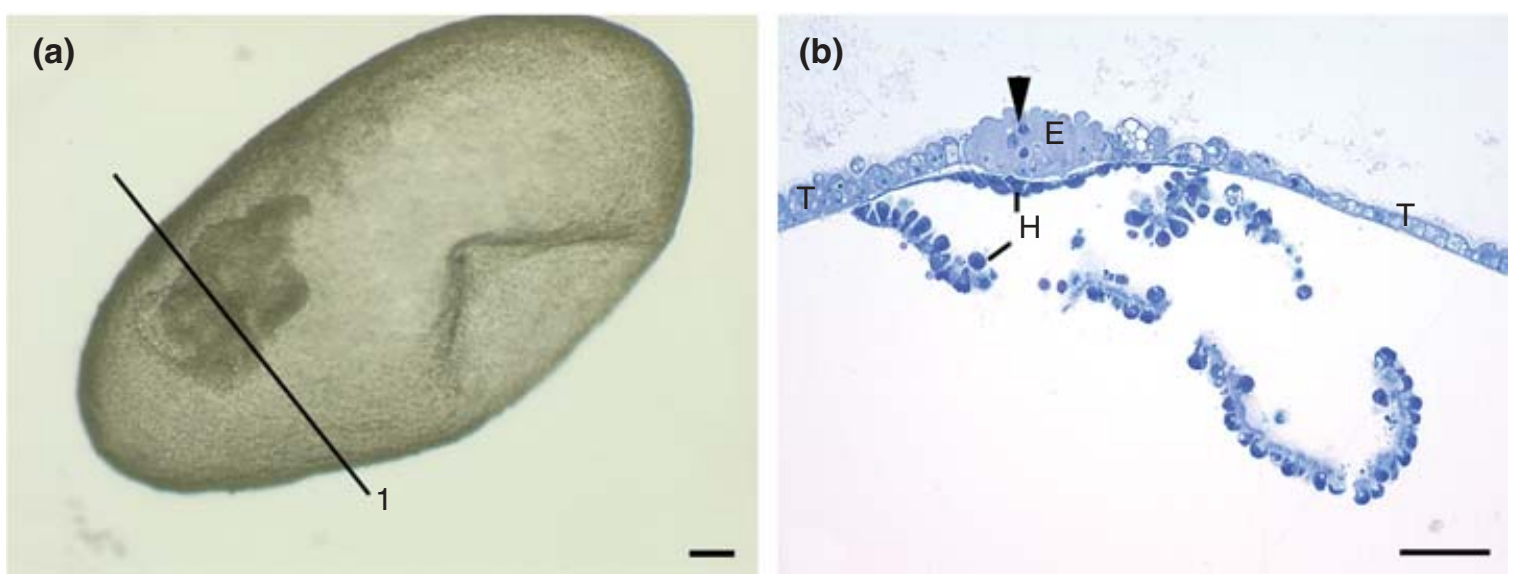

Fig. 7. Day 14 bovine embryo undergoing early embryonic mortality. (a) An ovoid embryo with a dark entity associated with the embryonic disc as seen through a stereomicroscope. (b) Light micrograph of a section oriented as line 1 in (a). Note the epiblast (E) with several apparently apoptotic nuclei (arrowhead), and the hypoblast $(\mathrm{H})$ which is released from its normal position underlying the trophoblast (T). Scale bars represent (a) $0.1 \mathrm{~mm}$ and (b) $50 \mu \mathrm{m}$.

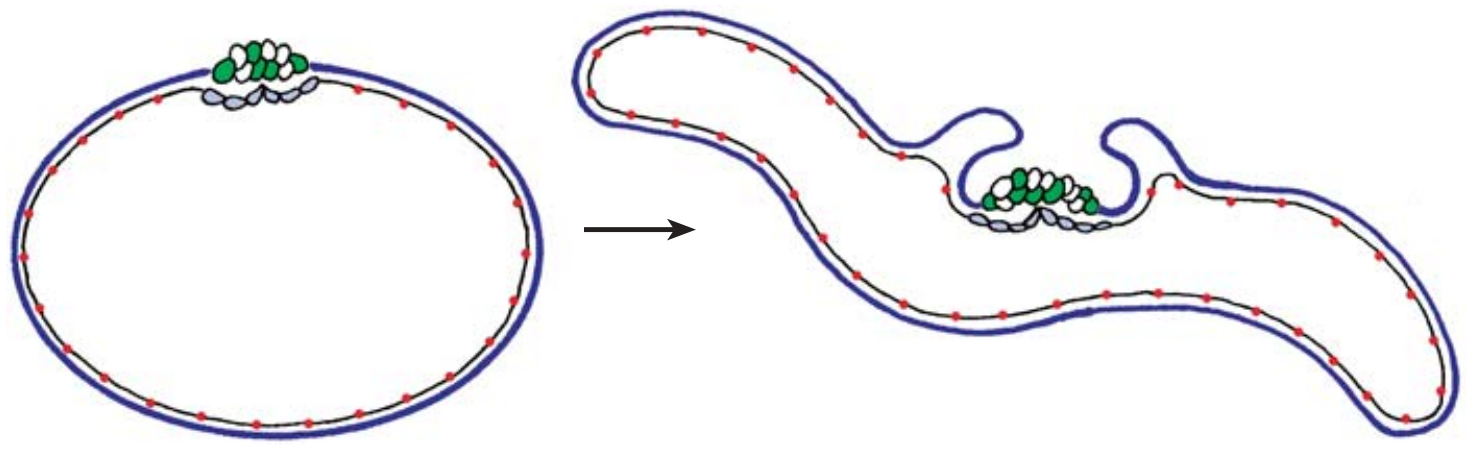

Fig. 8. Schematic diagram of the immunohistochemical labelling for cytokeratin 8 (blue), alpha-1-fetoprotein (red) and vimentin (green) of bovine embyos on day 14 . The intensity of the colour indicates the intensity of the labelling. Cytokeratin 8 labelling is seen in the trophoblast and to some extent in the hypoblast underlying the epiblast. Alpha-1-fetoprotein labelling is seen in most hypoblast cells. Vimentin labelling is seen in most epiblast cells.
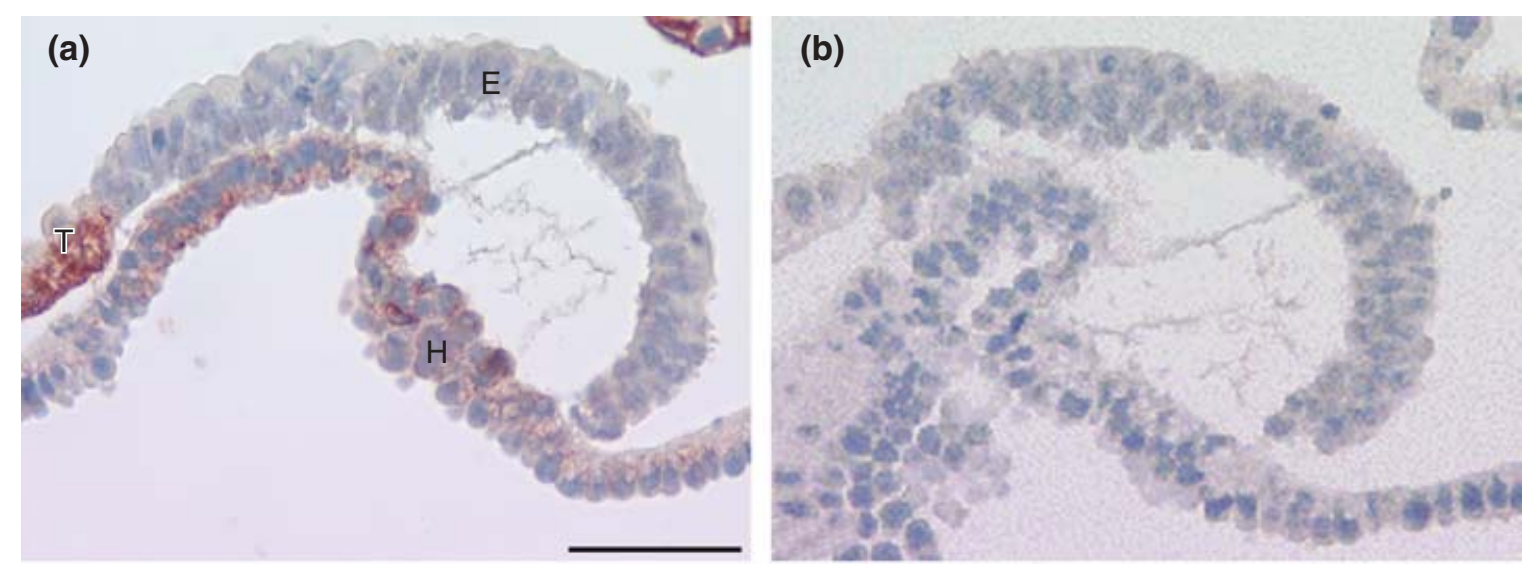

Fig. 9. Cytokeratin 8 labelling of day 14 bovine embryo. (a) Labelling is seen in the trophoblast (T) and to some extent in the hypoblast $(\mathrm{H})$ underlying the epiblast (E). (b) Negative control corresponding to (a). Scale bar represents $50 \mu \mathrm{m}$. 

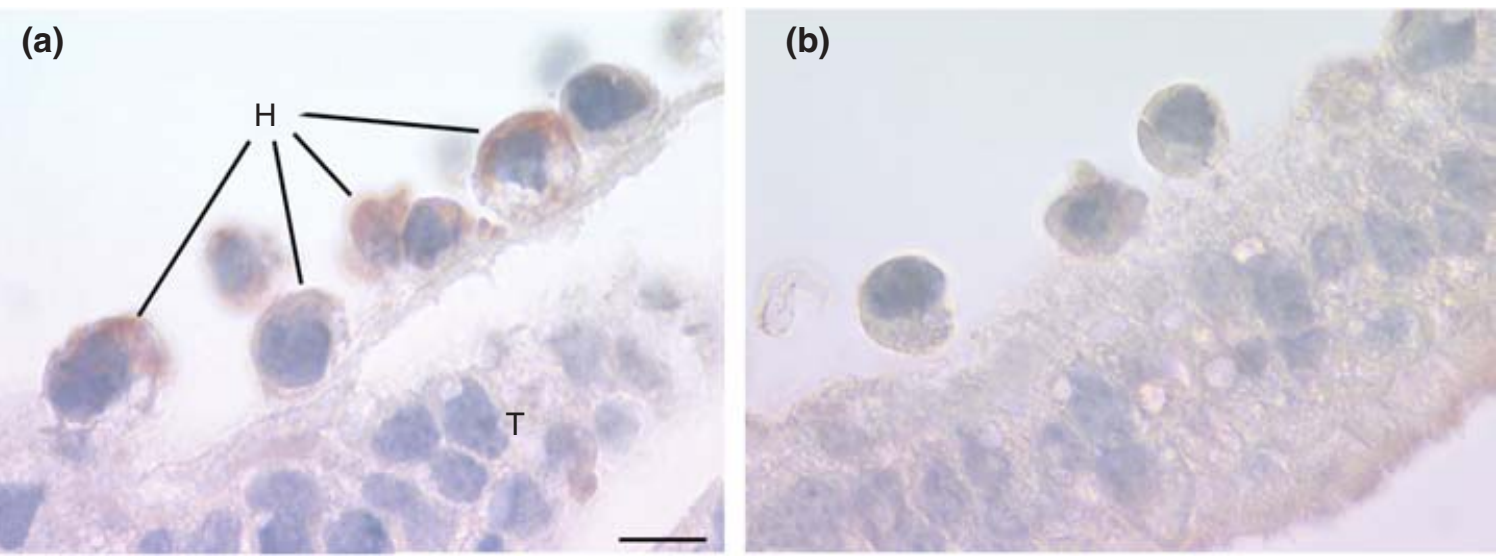

Fig. 10. Alpha-1-fetoprotein labelling of day 14 bovine embryo. (a) Labelling is seen in most hypoblast cells $(H)$ underlying the trophoblast (T). (b) Negative control corresponding to (a). Scale bar represents $10 \mu \mathrm{m}$.
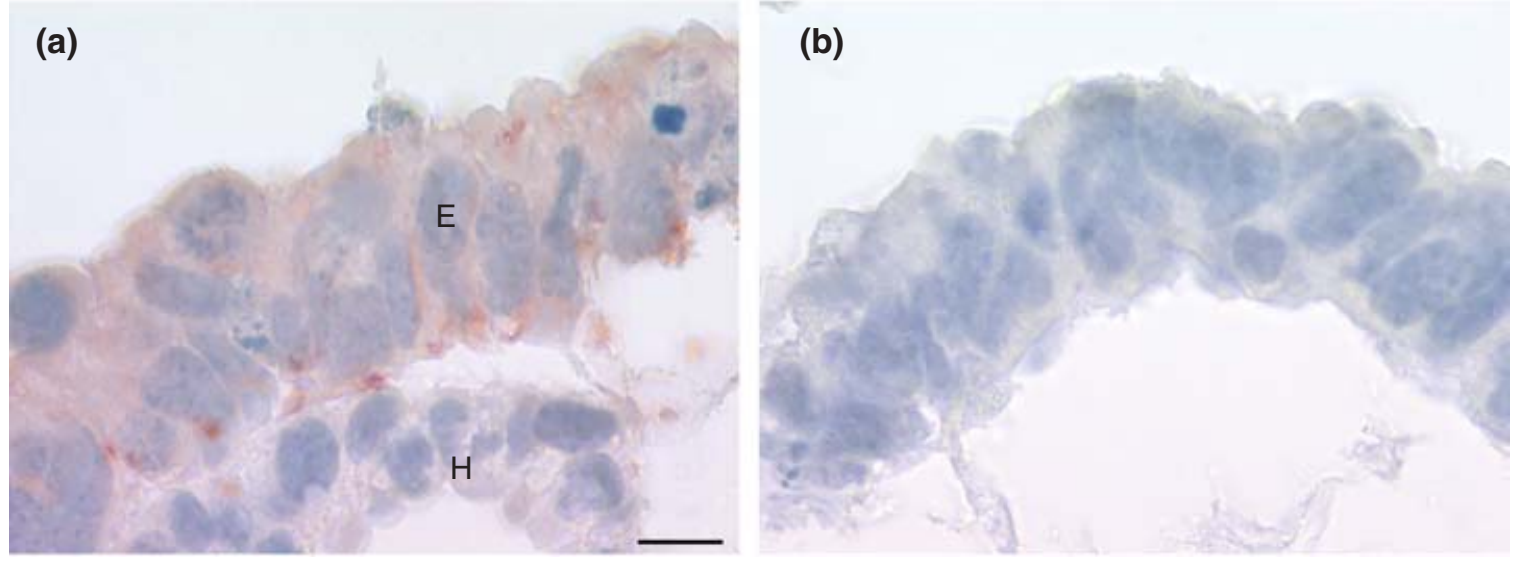

Fig. 11. Vimentin labelling of day 14 bovine embryo. (a) Labelling is seen in most epiblast cells (E) on top of the hypoblast (H). (b) Negative control corresponding to (a). Scale bar represents $10 \mu \mathrm{m}$.
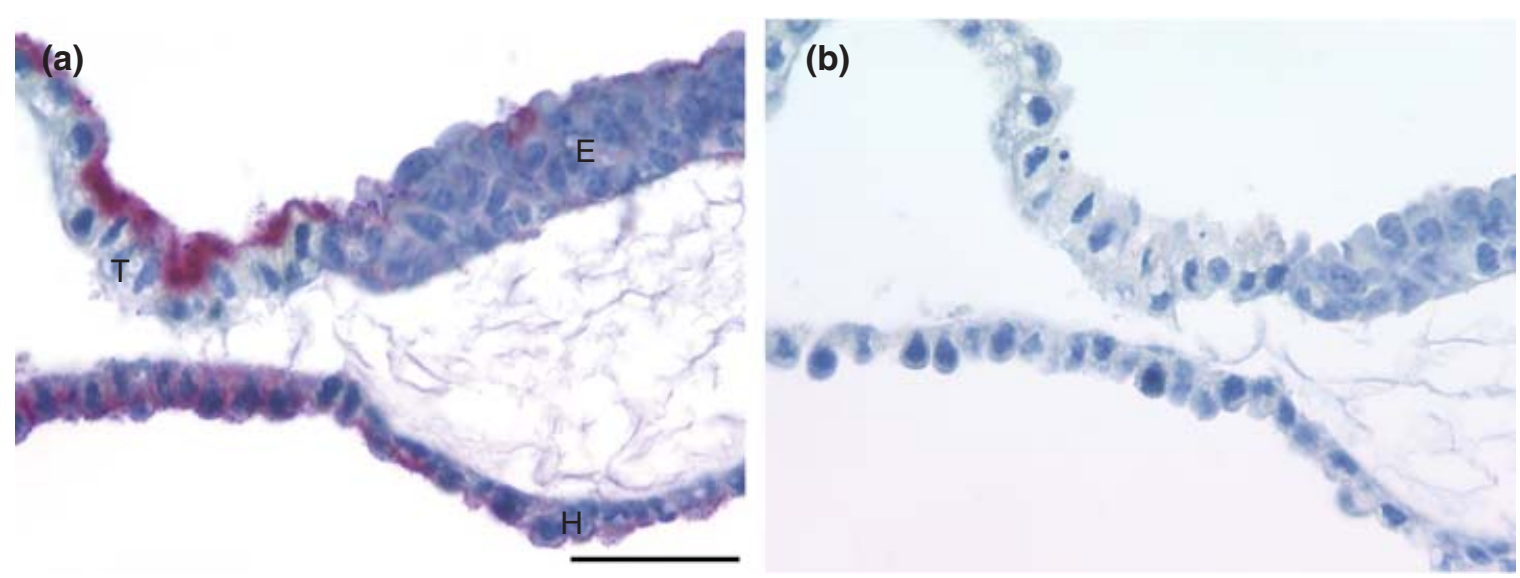

Fig. 12. Alkaline phosphatase staining of day 14 bovine embryo. (a) Staining is seen in the trophoblast (T) and to some extent the hypoblast $(\mathrm{H})$, but not in the epiblast (E). (b) Negative control corresponding to (a). Scale bar represents $50 \mu \mathrm{m}$. 

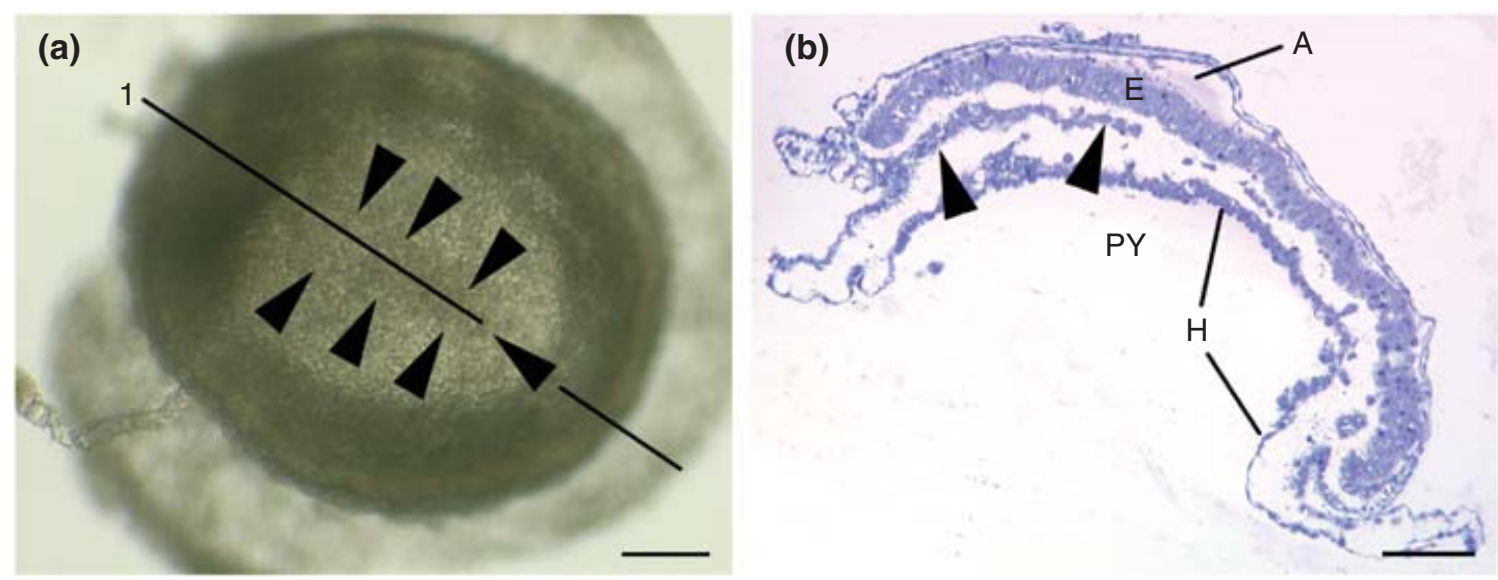

Fig. 13. Day 21 bovine embryo. (a) An embryo presenting the primitive streak (delineated by arrowheads) as seen under a stereomicroscope. (b) Light micrograph of a transection oriented as line 1 in (a). Note the amniotic cavity (A) enclosing the epiblast (E) under which a mass of precursor cells for the definitive endoderm and mesoderm extends cranially (arrowheads). Ventrally, the primitive yolk sac (PY) is delineated by the hypoblast (H). Scale bars represent (a) $0.1 \mathrm{~mm}$ and (b) $100 \mu \mathrm{m}$.
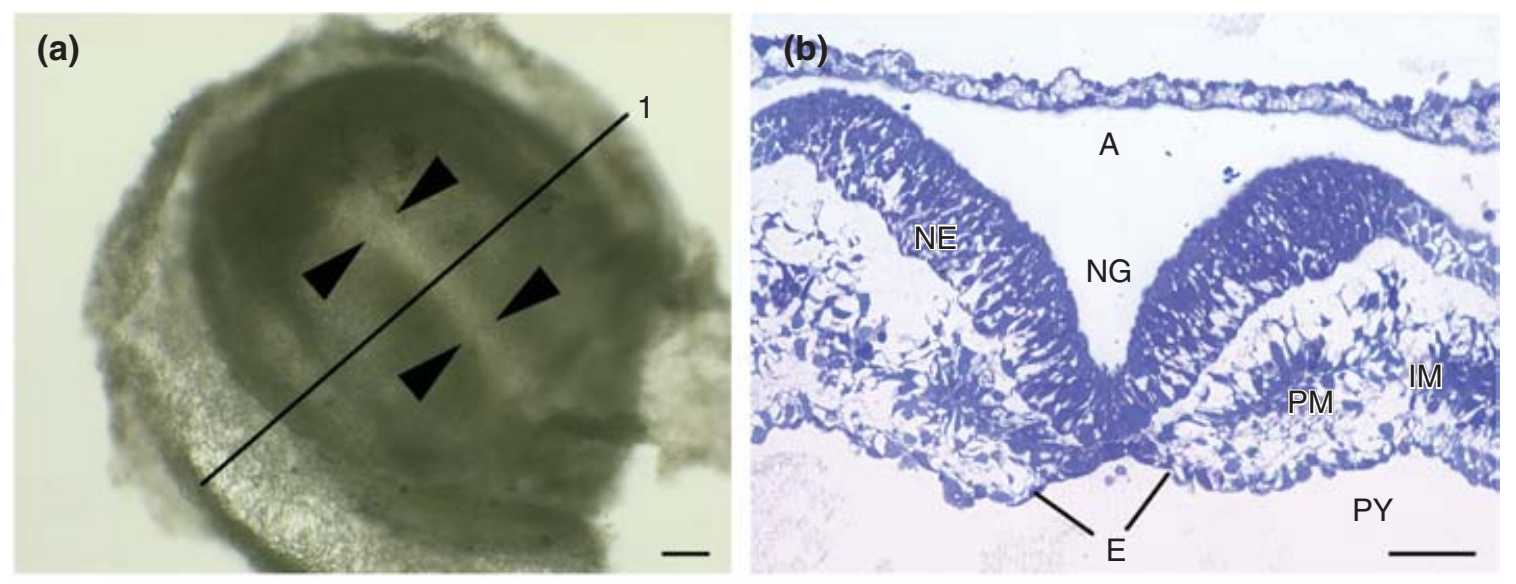

Fig. 14. Day 21 bovine embryo. (a) An embryo presenting the neural groove (delineated by arrowheads) as seen under a stereomicroscope. (b) Light micrograph of a section oriented as line 1 in (a). Note the neural groove (NG) delineated by neural ectoderm (NE) and opening into the amniotic cavity (A). Also, paraxial (PM) and intermediate mesoderm (IM) are seen. The primitive yolk sac (PY) is proximally delineated by definitive endoderm (E). Scale bars represent (a) $0.1 \mathrm{~mm}$ and (b) $50 \mu \mathrm{m}$.

portion of the hypoblast epithelium. Labelling for alpha1 -fetoprotein was found in many, but not all, hypoblast cells, but not in the definitive endoderm. Labelling for vimentin was observed in cells scattered in the ventral region of the primitive streak, in the mesoderm as well as in the definitive endoderm, but not in the rest of the epiblast (Fig. 18a,b).

In embryos at the neural groove stage, weak labelling for cytokeratin 8 was seen in the trophoblast lining the inside of the amniotic cavity as well as in the surface and neural ectoderm and the definitive endoderm, whereas the hypoblast displayed strong labelling (Fig. 17). Labelling for alpha-1-fetoprotein was found in the hypoblast, but not in the definitive endoderm.
Labelling for vimentin was observed in all mesoderm components including the notochord.

In embryos at the neural tube stage, weak labelling for cytokeratin 8 was seen in the trophoblast lining the inside of the amniotic cavity and in the ectoderm, whereas the definitive endoderm and the hypoblast displayed strong labelling (Figs 17 and 19a,b). Labelling for alpha-1-fetoprotein was found in the total hypoblast, but not in the definitive endoderm (Fig. 20a,b). Weak labelling for vimentin was observed in the neural tube, the somites and the intermediate mesoderm, whereas the somatic and splanchnic mesoderm, in particular the blood vessels, displayed strong labelling (Fig. 21a,b). 

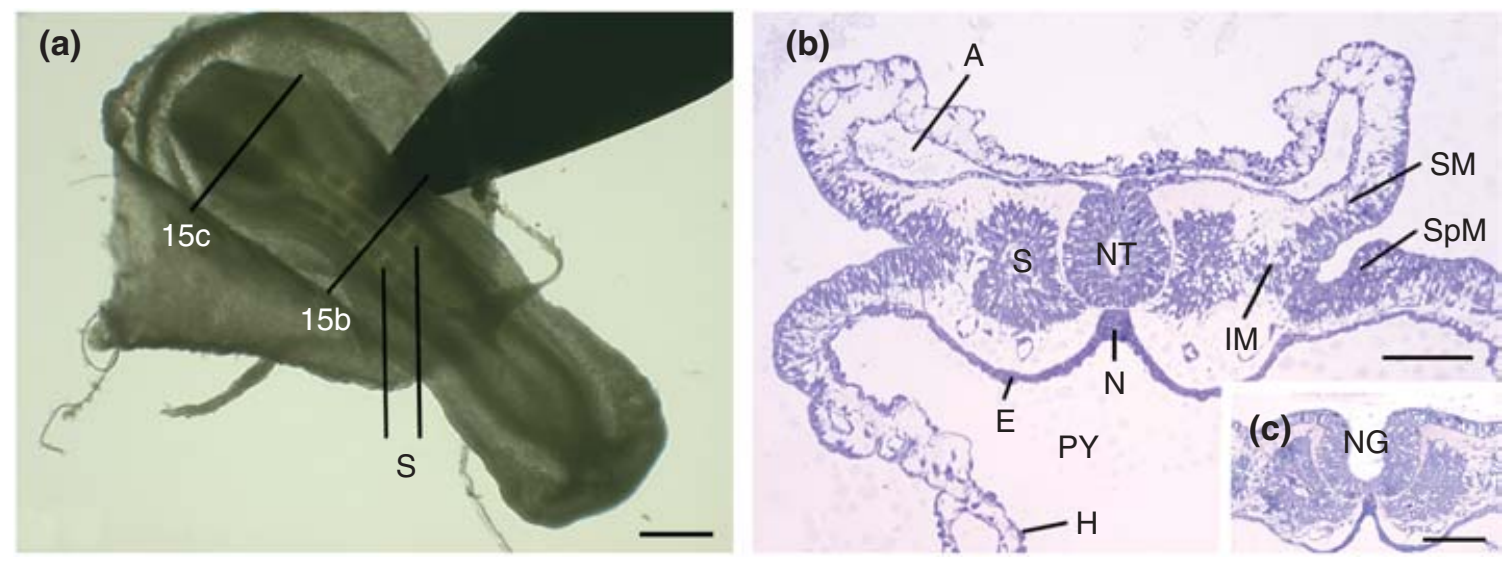

Fig. 15. Day 21 bovine embryo. (a) An embryo presenting somites (S) as seen under a stereomicroscope. (b) Light micrograph of a section oriented as line $15 \mathrm{~b}$ in (a). Note the amniotic cavity (A), the neural tube (NT), the somites (S), the intermediate mesoderm (IM), the somatic mesoderm (SM) and the splanchnic mesoderm (SpM). The primitive yolk sac $(\mathrm{PY})$ is delineated by definitive endoderm (E) proximally and hypoblast $(\mathrm{H})$ distally. The notochord $(\mathrm{N})$ is attached to the endoderm. (c) Light micrograph of a section oriented as line $15 \mathrm{c}$ in (a). Note the neural groove (NG) defining the rostral neuropore. Scale bars represent (a) $0.5 \mathrm{~mm}$ and (b,c) $100 \mu \mathrm{m}$.

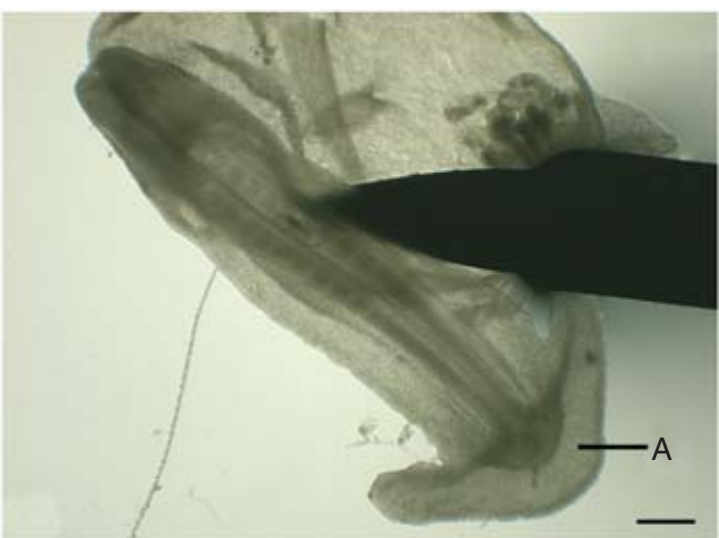

Fig. 16. Day 21 bovine embryo showing the development of the allantois (A), as seen under a stereomicroscope. Scale bar represents $0.5 \mathrm{~mm}$.

\section{Discussion}

On the basis of light and transmission electron microscopy, the present investigation clearly defines a set of stages in initial bovine post-hatching embryonic development. Furthermore, some of the underlying functional aspects were elucidated by immunocytochemistry.

On day 9 , shortly after hatching from the zona pellucida, the hypoblast formation was ongoing as evidenced by delamination of cells from the ICM in accordance with previous findings (Betteridge and Fléchon, 1988). On day 11 , the hypoblast formed a very thin but confluent lining on the inside of the ICM and the trophoblast. With the completion of hypoblast formation it is reasonable to refer to the remaining portion of the ICM as the epiblast. An extracellular matrix is presumably required to allow for the rapid propagation of the hypoblast. Indeed, on day 11 it was possible to visualize the extracellular matrix between the hypoblast on the one hand and the ICM and the trophoblast on the other. Immunocytochemical studies on bovine embryos produced in vitro have demonstrated that fibronectin underlies the ICM from day 7 , whereas in day 13 embryos this matrix protein is found between hypoblast and trophoblast, but not between hypoblast and epiblast (Shehu et al., 1996). The same authors also demonstrated localization of laminin and collagen IV between hypoblast and trophoblast. These data support the findings of the present study, although the extracellular matrix was consistently found in relation to the epiblast in the present study.

During the formation of the hypoblast, the embryo prepares for establishment of the embryonic disc from the epiblast. On day 9 in the present study, the trophoblast was cuboidal except in the Rauber's layer, where it formed a thin cellular sheet in which the cells, however, were still connected by tight junctions and desmosomes. The outer cells of the ICM became closely apposed with interdigitating plasma membranes preparing to form the external layer of the embryonic disc. This process was followed on day 11 by what appeared to be the formation of tight junctions between adjacent outer cells of the ICM, that is, the epiblast. Concomitantly, degeneration of cells of the trophoblast forming the Rauber's layer was seen in accordance with observations in pig and sheep blastocysts (Fléchon, 1978). Through this process, the epiblast becomes exposed to the external environment and establishes the embryonic disc.

The elongation of the conceptuses was ongoing on day 14. A marked variation in length was noticed between embryos in accordance with previous data (Betteridge and Fléchon, 1988). It is unknown whether 


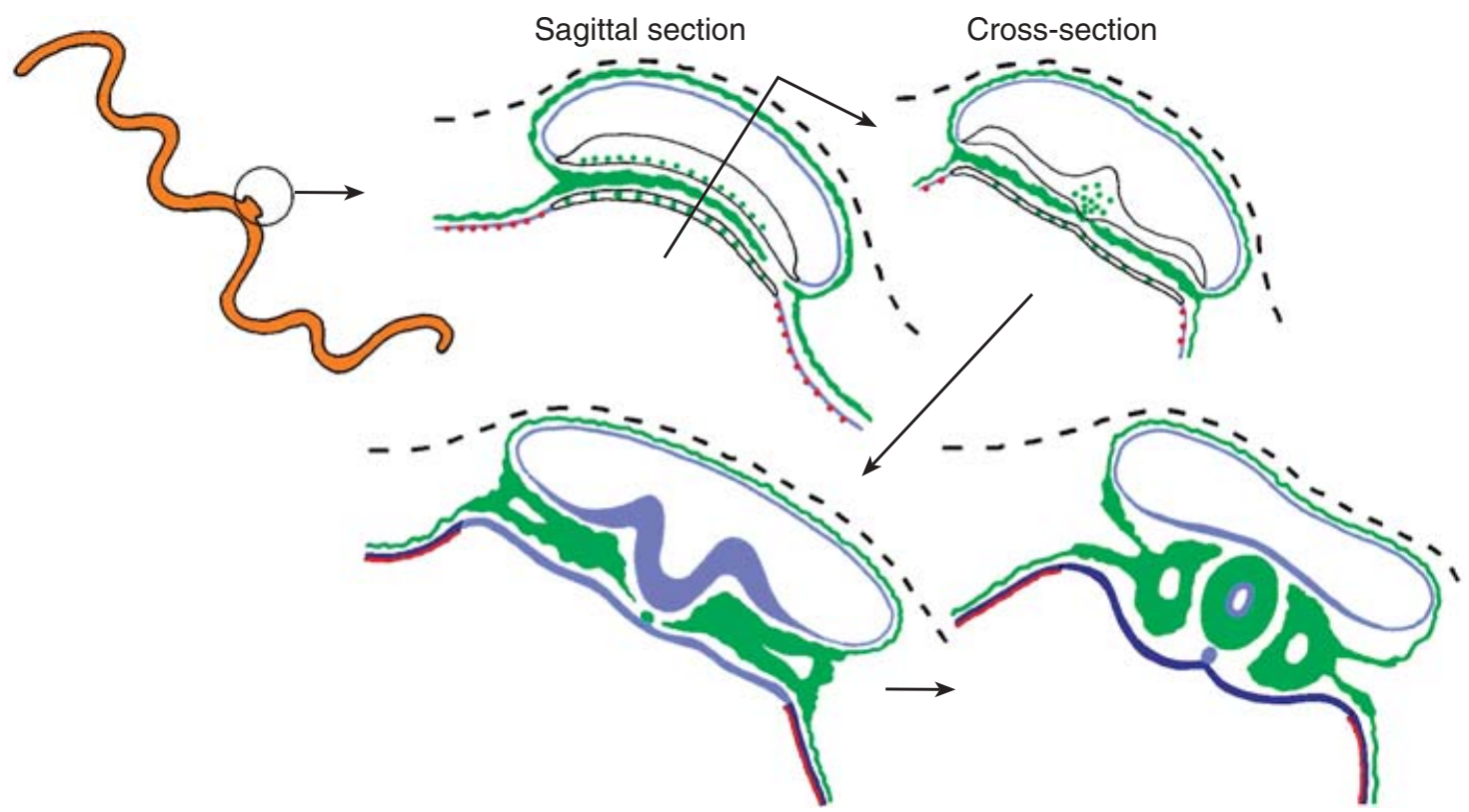

Fig. 17. Schematic diagram of the immunohistochemical labelling for cytokeratin 8 (blue), alpha-1-fetoprotein (red) and vimentin (green) of bovine embryos on day 21 . The intensity of the colour indicates the intensity of the labelling. The upper two drawings are sagittal and cross-sections of primitive streak stage embryos, whereas the lower drawings are neural groove and neural tube stage embryos. Cytokeratin 8 labelling is seen in the trophoblast lining the inside of the amniotic cavity (all stages), the ectoderm (neural groove and tube stages), the hypoblast (all stages) and the definitive endoderm (neural groove and tube stages). Alpha-1-fetoprotein labelling is seen in the hypoblast. In the primitive streak embryos, vimentin labelling is seen in some cells in the ventral epiblast, in the developing definitive endoderm and mesoderm. In the neural groove and tube stages, all components of the mesoderm display vimentin labelling. The black line indicates the tentative position of the removed trophoblast.
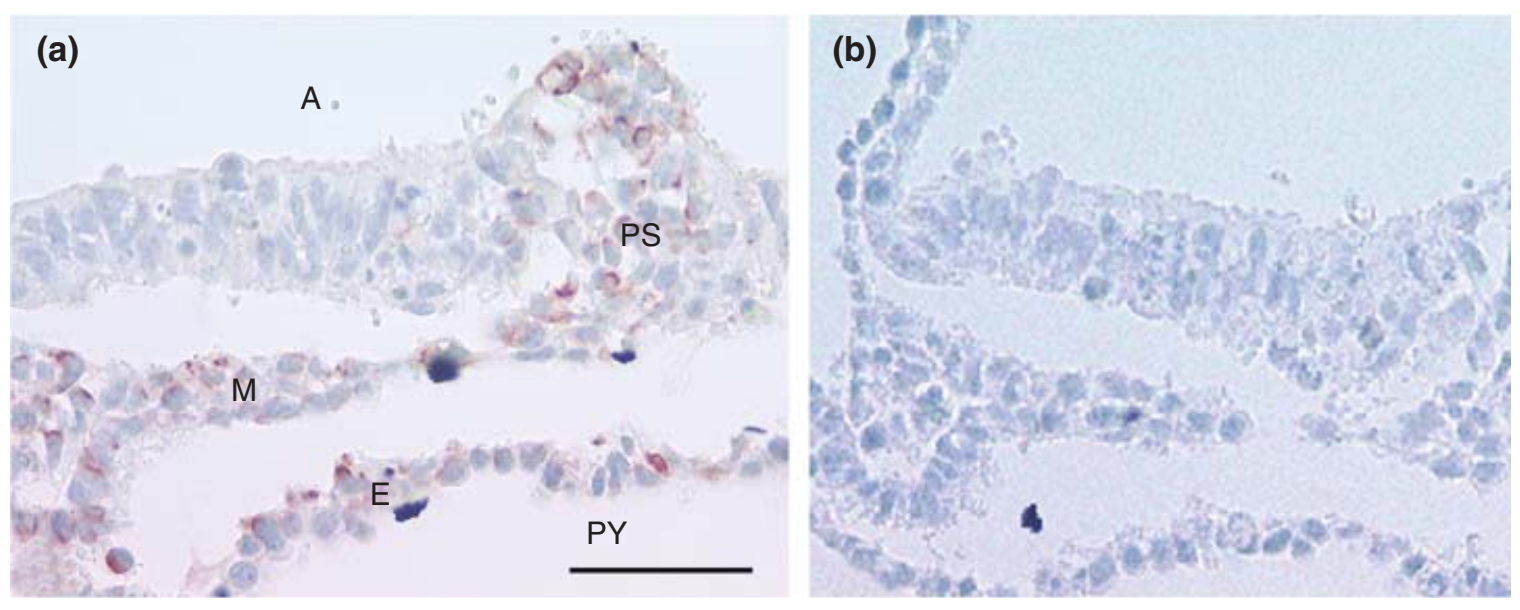

Fig. 18. Vimentin labelling of cross-section of day 21 bovine embryo. (a) Labelling is seen in cells in the primitive streak (PS), mesoderm (M) and definitive endoderm (E) delineating the primitive yolk sac (PY). The amniotic cavity (A) is seen at the top. (b) Negative control corresponding to (a). Scale bar represents $50 \mu \mathrm{m}$.

the superovulation procedure added to this phenomenon. The embryonic disc could be identified in most embryos. Initially, the disc was poorly delineated and transluscent, but later it formed a very distinct bulge, as reported by Winters et al. (1942). The outer cells of the epiblast were connected to each other and to the adjacent trophoblast cells by tight junctions and desmosomes forming a continuous epithelium. The intermediate filament cytokeratin 8 , which is characteristic for simple epithelia and which is related to the desmosomes, was localized to the trophoblast, highlighting strong epithelial characteristics. However, the epiblast did not present labelling for this protein, indicating less prominent epithelial differentiation. Cytokeratins have 

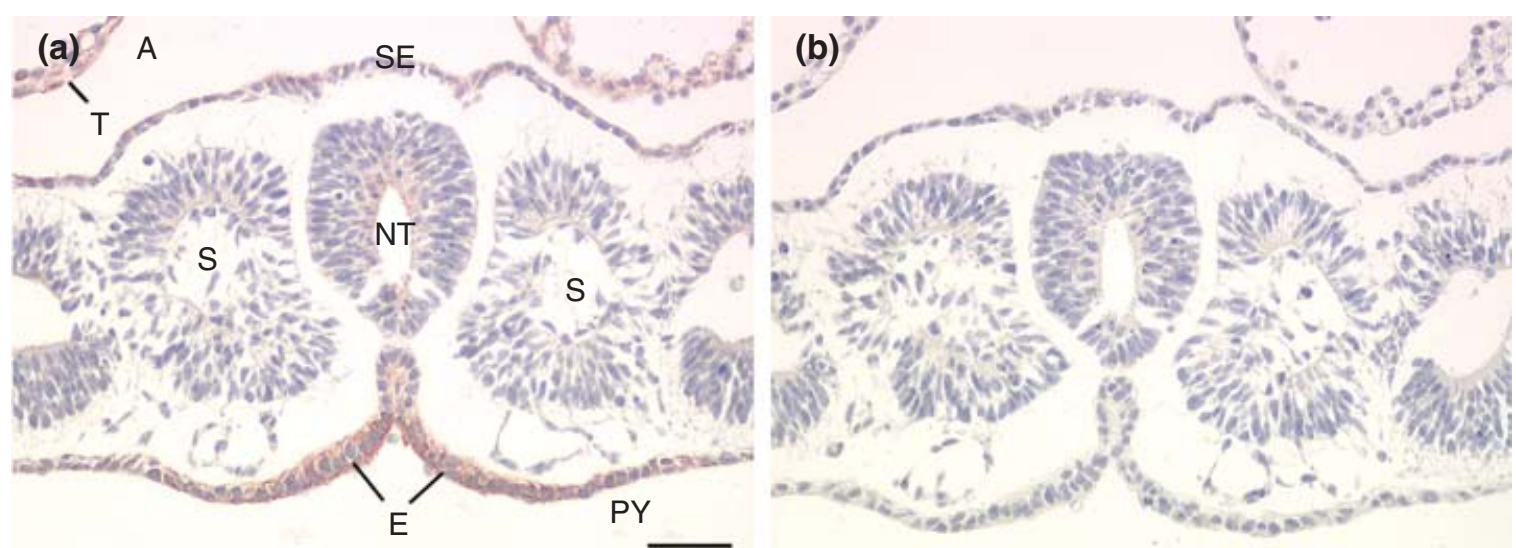

Fig. 19. Cytokeratin 8 labelling of day 21 bovine embryo. (a) Labelling is seen in the trophoblast (T) lining the inside of the amniotic cavity (A), the surface epithelium (SE), the neural tube (NT), and, in particular, the definitive endoderm (E) lining the primitive yolk sac (PY). The somites (S) are not labelled. (b) Negative control corresponding to (a). Scale bar represents $50 \mu \mathrm{m}$.
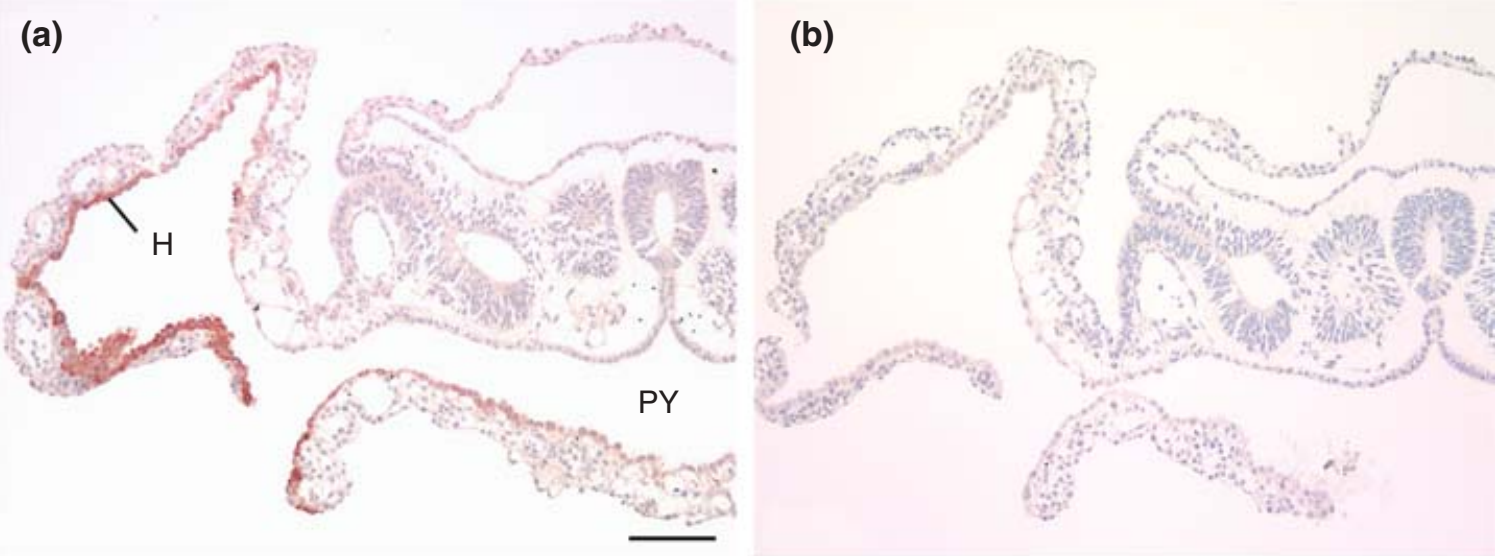

Fig. 20. Alpha-1-fetoprotein labelling of day 21 bovine embryo. (a) Labelling is seen in the hypoblast $(\mathrm{H})$ delineating the primitive yolk sac (PY) distally. (b) Negative control corresponding to (a). Scale bar represents $100 \mu \mathrm{m}$.
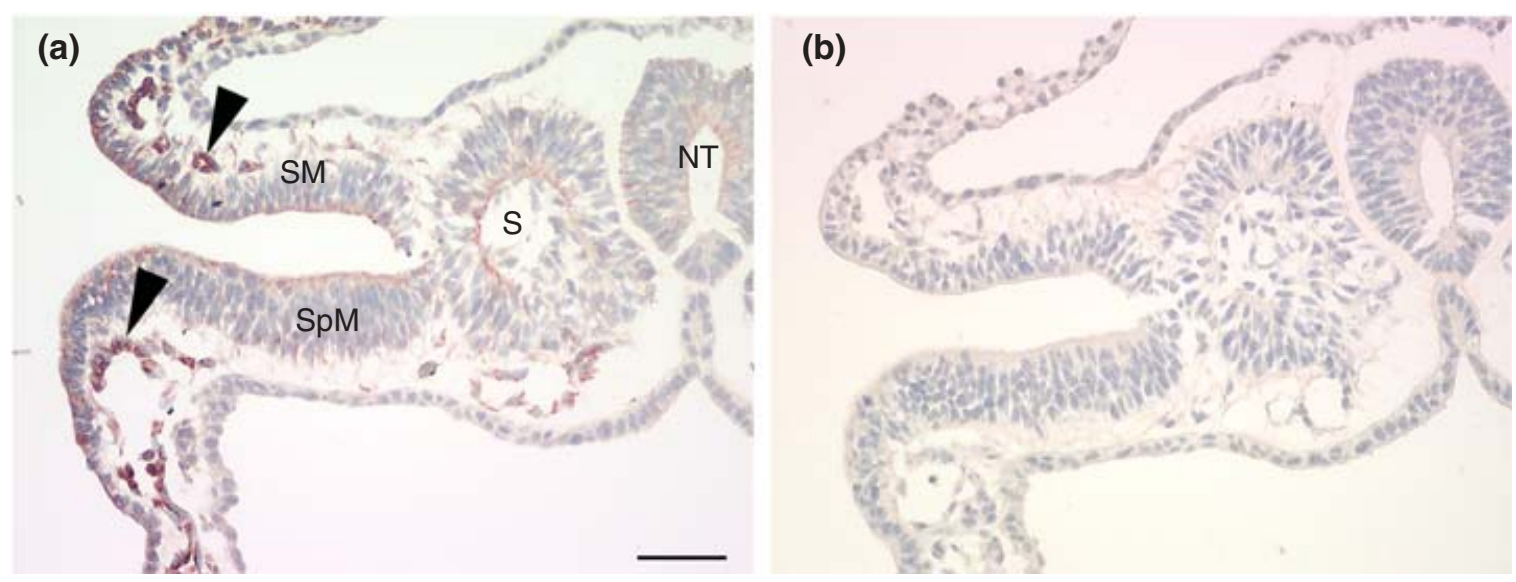

Fig. 21. Vimentin labelling of day 21 bovine embryo. (a) Labelling is seen in the neural tube (NT), the somites (S) and in the somatic (SM) and splanchnic mesoderm (SpM) in particular in the blood vessels (arrowheads). (b) Negative control corresponding to (a). Scale bar represents $50 \mu \mathrm{m}$. 
previously been localized to the trophoblast of bovine embryos at day 7 (Shehu et al., 1996). In accordance with the observations of the present study, these authors did not demonstrate labelling of the ICM and the epiblast.

The epiblast cells are pluripotent. In previous studies on in vitro cultured epiblasts from pig and ovine (Talbot et al., 1993) as well as bovine (Talbot et al., 1995) embryos, alkaline phosphatase staining has been used as one of several positive morphological markers of pluripotency. In the present experiment, no alkaline phosphatase staining could be demonstrated in the epiblast. On the contrary, the trophoblast and to some extent the hypoblast developed staining without any staining of the epiblast. The reason for this difference from the cited results is unknown, but it is possible that the culture conditions used by the cited authors contributed to the visualized alkaline phosphatase activity.

All day 14 embryos displayed a complete hypoblast. The portion of this cell layer underlying the epiblast displayed some cytokeratin labelling, and thus, clear epithelial characteristics. Most cells in the hypoblast underlying the trophoblast, but not in the hypoblast underlying the epiblast, displayed alpha-1-fetoprotein labelling. This is the opposite of what occurs in the mouse embryo, in which the hypoblast lacks such labelling (Dziadek and Adamson, 1978). In a previous report on bovine embryos, the earliest synthesis developmentally of alpha-1-fetoprotein was demonstrated in the trophoblast on day 14 and the protein was found in the allantoic fluid on day 16 (Janzen et al., 1982). The onset of alpha1 -fetoprotein synthesis on day 14 is in accordance with the immunohistochemical localization of the protein at that stage of development in the present study. However, the hypoblast rather than the trophoblast appears to be the site of synhthesis. Moreover, it seems unlikely that the protein could be demonstrated in allantoic fluid on day 16 when allantoic development, according to the present observations, has not progressed to a stage at which this compartment can be identified. Most likely, the examined fluid originated from the yolk sac.

In some embryos on day 14 , the formation of trophoblast folds adjacent to the embryonic disc marked the initial formation of the amniotic cavity. Thus, both the inner and outer epithelium of the amniotic cavity is of trophoblast origin.

A pronounced elongation of the conceptuses occurred between day 14 and day 21 . The amniotic cavity had formed in all cases and there was a marked variation in embryonic development ranging from formation of the primitive streak over neurulation to the formation of somites and allantois in accordance with earlier observations (Winters et al., 1942; Betteridge and Fléchon, 1988). Cytokeratin labelling was distributed through practically all epithelia including the neural ectoderm, which is not labelled in the chicken embryo (Page, 1989).
Gastrulation is a process involving complex cellular migrations including first an ingression of cells from the epiblast to form the primitive streak and, second, an involution of cells through this structure to form definitive endoderm and mesoderm. At least in the chicken embryo, it has been demonstrated that certain cells scattered in the epiblast can be distinguished by a particular molecule on the plasma membrane (HNK-1, a sulphated form of glucuronic acid; Stern, 1992). These cells ingress from the epiblast to the space between the epiblast and the hypoblast where they converge in the caudal pole of the embryonic disc to form the primitive streak. The streak grows in a cranial direction and the so-called Hensen's node is formed at its most cranial end. As the next step of gastrulation, epiblast cells involute through the node to form the definitive endoderm, which is inserted into the upper portion of the hypoblast epithelium, and the mesoderm of the dorsal axis including the notochord. Furthermore, epiblast cells involuting through the primitive streak give rise to more lateral mesoderm.

Comparable mechanisms apparently operate in the bovine embryo. The initial formation of precursor cells for the primitive streak was noticed on day 14 , where ingression of cells from the internal surface of the epiblast took place. It has been demonstrated that in bovine embryos these cells express the transcription factor Brachyury, a marker for mesoderm formation, as also reported in murine and human embryos (Hue et al., 2001). The ingressed cells appeared to accumulate in the tentative caudal region of the embryonic disc, thus preparing for the formation of the primitive streak. In both chicken and mouse embryos, a shift in the intermediate filament population of the cells destined to involute through the node and the primitive streak is seen (Jackson et al., 1981; Franke et al., 1982; Page, 1989). Thus, the cytokeratins, characterizing the epiblast in these species, are lost and vimentin filaments appear instead, characterizing the motile cells with the potential of leaving the epiblast. A similar occurrence of vimentin filaments was observed during bovine gastrulation. Thus, before the process of ingression of epiblast cells to form the primitive streak was initiated, cells scattered in the epiblast already displayed vimentin labelling. These cells are presumably those destined either to ingress to form the streak or to involute through the streak to form definitive endoderm and mesoderm, as also assumed to occur in the chicken embryo (Page, 1989). On day 21 in the present study, bovine embryos with a full primitive streak from which cells involuted to form definitive endoderm and mesoderm were encountered. Again, numerous cells scattered in the primitive streak displayed vimentin labelling, as did many cells in the mesoderm and definitive endoderm. This labelling pattern clearly substantiates the involution of vimentin-expressing cells from the primitive streak to form both endoderm and mesoderm. 
During gastrulation, the hypoblast attained increased labelling for both cytokeratin and alpha-1-fetoprotein, whereas the endoderm cells, initially being inserted into the hypoblast, lacked labelling for both of these proteins. However, over time, as the vimentin labelling of the endoderm was lost, cytokeratin labelling appeared. In a similar way, only very limited co-expression of cytokeratin and vimentin is observed in the chicken embryo (Page, 1989). However, labelling for alpha1 -fetoprotein was never established in the definitive endoderm in the present study. This pattern is the opposite to that observed in the mouse embryo in which the initial alpha-fetoprotein labelling is observed only in the definitive endoderm of the embryonic region of the egg cylinder, and not in the hypoblast (Dziadek and Adamson, 1978).

The immunohistochemical characterization aimed at reflecting histogenic lineage. However, from the present results as well as those obtained earlier in chicken (Page, 1989) and mouse (Jackson et al., 1981) embryos, it is clear that the expression of the intermediate filaments cytokeratin 8 and vimentin appears to be more related to functional and behavioural requirements than to germlayer derivation.

In conclusion, within 2 weeks of hatching, bovine embryos complete a series of well-defined stages allowing for the establishment of the embryo proper with its associated membranes. These stages are formation of the hypoblast and epiblast, establishment of the amniotic cavity, ingression of epiblast cells for primitive streak formation, involution of cells through the node and the streak for definitive endoderm and mesoderm formation, neurulation and differentiation of the mesoderm. The recruitment of cells from the epiblast to form the primitive streak as well as the definitive endoderm and mesoderm is associated with expression of the intermediate filament vimentin.

The authors would like to acknowledge the technical assistance of J. Nielsen. The work was supported by the Alfred Benzon's Foundation and the Danish Agricultural and Veterinary Research Council.

\section{References}

Bertolini M and Anderson GB (2002) The placenta as a contributor to production of large calves Theriogenology 57 181-187

Betteridge KJ and Fléchon J-E (1988) The anatomy and physiology of preattachment bovine embryos Theriogenology 29 155-187

Betteridge KJ, Eaglesome MD, Randall GCB and Mitchell D (1980) Collection, description and transfer of embryos from cattle 10-16 days after oestrus Journal of Reproduction and Fertility $\mathbf{5 9}$ 205-216

Booth PJ, Viuff D, Thomsen PD, Holm P, Greve T and Callesen H (2000) Ploidy of bovine nuclear transfer blastocysts reconstructed using in vitro produced blastomere donors Cloning 2 63-68

Chang MC (1952) Development of bovine blastocyst with a note on implantation Anatomical Records 113 143-161

Daniels R, Hall V and Trounson AO (2002) Analysis of gene transcription in bovine nuclear transfer embryos reconstructed with granulosa cells Biology of Reproduction 63 1034-1040
De Sousa PA, King T, Harkness L, Young LE, Walker SK and Wilmut I (2001) Evaluation of gestational deficiencies in cloned sheep fetuses and placentae Biology of Reproduction 65 23-30

Dziadek M and Adamson E (1978) Localization and synthesis of alphafoetoprotein in post-implantation mouse embryos Journal of Embryology and Experimental Morphology 43 289-313

Fléchon J-E (1978) Morphological aspects of embryonic disc at the time of its appearance in the blastocyst of farm mammals Scanning Electron Microscopy II 541-548

Franke WW, Grund C, Kuhn C, Jackson BW and Illmensee K (1982) Formation of cytoskeletal elements during mouse embryogenesis. III. Primary mesenchymal cells and the first appearance of vimentin filaments Differentiation 23 43-59

Gjørret JO, Avery B, Larsson L-I, Schellander K and Hyttel P (2001) Apoptosis in bovine blastocysts produced in vivo and in vitro. Theriogenology 55321 (Abstract)

Gjørret JO, Wengle J, King WA, Schellander K and Hyttel P (2002) Occurrence of apoptosis in bovine embryos reconstructed by nuclear transfer or derived in vivo. Theriogenology 57495 (Abstract)

Greenstein JS and Foley RC (1958) Early embryology of the cow. I. Gastrula and primitive streak stages Journal of Dairy Science $\mathbf{4 1} 409$ 421

Guillomot M (1995) Cellular interactions during implantation in domestic ruminants Journal of Reproduction and Fertility Supplement $\mathbf{4 9}$ 39-51

Gustafsson H and Ploen L (1986) The morphology of 16 and 17 day old bovine blastocysts from virgin and repeat breeder heifers Anatomy, Histology and Embryology 15 277-287

Heyman Y, Chavatte-Palmer P, DeBourhis D, Camous S, Vignon X and Renard JP (2002) Frequency and occurrence of late-gestation losses from cattle cloned embryos Biology of Reproduction 66 6-13

Hill JR, Roussel AJ, Cibelli JB et al. (1999) Clinical and pathologic features of cloned transgenic calves and fetuses (13 case studies) Theriogenology 51 1451-1465

Hill JR, Burghard RC, Jones K, Long C, Looney C, Shin T, Spencer T, Thompson J, Winger Q and Westhusin ME (2000) Evidence for placental abnormality as a major cause of mortality in first-trimester somatic cell cloned bovine fetuses Biology of Reproduction 63 1787-1794

Hue I, Renard J-P and Viebahn C (2001) Brachyury is expressed in gastrulating bovine embryos well ahead of implantation Development, Genes and Evolution 211 157-159

Hyttel P and Madsen I (1987) Rapid method to prepare mammalian oocytes and embryos for transmission electron microscopy Acta Anatomica 129 12-14

Hyttel P, Laurincik J, Zakhartchenko V, Stojkovic M, Wolf E, Müller M, Ochs RL and Brem G (2001) Nucleolar protein allocation and ultrastructure in bovine embryos produced by nuclear transfer from embryonic cells Cloning 3 69-81

Jackson BW, Grund C, Winter S, Franke WW and IIImensee K (1981) Formation of cytoskeletal elements during mouse embryogenesis. II. Epithelial differentiation and intermediate-sized filaments in early postimplantation embryos Differentiation 20 203-216

Janzen RG, Mably ER, Tamaoki T, Church RB and Lorscheider FL (1982) Synthesis of alpha-fetoprotein by the pre-implantation and postimplantation bovine embryo Journal of Reproduction and Fertility 65 105-110

Laurincik J, Zakhartchenko V, Stojkovic M, Brem G, Wolf E, Muller M, Ochs RL and Maddox-Hyttel P (2002) Nuclear protein allocation and ultrastructure in bovine embryos produced by nuclear transfer from granulosa cells Molecular Reproduction and Development $\mathbf{6 1}$ $477-487$

Niemann H and Wrenzycki C (2000) Alterations of expression of developmentally important genes in preimplantation bovine embryos by in vitro culture conditions: implications for subsequent development Theriogenology 53 21-34

Niemann H, Wrenzycki C, Lucas-Hahn A, Brambrink T, Kues WA and Carnwath JW (2002) Gene expression patterns in bovine in vitroproduced and nuclear transfer-derived embryos and their implications for early development Cloning Stem Cells 4 29-38 
Page M (1989) Changing patterns of cytokeratins and vimentin in the early chick embryo Development 105 97-107

Shehu D, Marsicano G, Fléchon J-E and Galli C (1996) Developmentally regulated markers of in vitro-produced preimplantation bovine embryos Zygote 4 109-121

Stern CD (1992) Mesoderm induction and development of the embryonic axis in amniotes Trends in Genetics 8 158-163

Talbot NC, Rexroad CE, Pursel VG and Powell AM (1993) Alkaline phosphatase staining of pig and sheep epiblast cells in culture Molecular Reproduction and Development 36 139-147

Talbot NC, Powell AM and Rexroad CE (1995) In vitro pluripotency of epiblasts derived from bovine blastocysts Molecular Reproduction and Development 42 35-52

Viuff D, Rickords L, Offenberg H, Hyttel P, Avery B, Greve T, Olsaker I, Williams JL, Callesen H and Thomsen PD (1999) A high proportion of bovine blastocysts produced in vitro are mixoploid Biology of Reproduction 60 1273-1278

Viuff D, Greve T, Avery B, Hyttel P, Brockhoff PB and Thomsen PD (2000) Chromosome aberrrations in in vitro-produced bovine embryos at days 2-5 post-insemination Biology of Reproduction 63 1143-1148
Viuff D, Hendriksen PJM, Vos PL, Dieleman SJ, Bibby BM, Greve T, Hyttel P and Thomsen PD (2001) Chromosomal abnormalities and developmental kinetics in in vivo-developed cattle embryos at days 2 to 5 after ovulation Biology of Reproduction 65 204-208

Wells D, Misica P and Tervit H (1999) Production of cloned calves following nuclear transfer with cultured adult mural granulosa cells Biology of Reproduction 60 996-1005

Winters LM, Green WW and Comstock RE (1942) Prenatal development of the bovine Minnesota Technical Bulletin 151 3-50

Wrenzycki C, Wells D, Herrmann D, Miller A, Oliver J, Tervit R and Niemann $\mathbf{H}$ (2001) Nuclear transfer protocol affects messenger RNA expression patterns in cloned bovine blastocysts Biology of Reproduction 65 309-317

Received 21 October 2002.

First decision 3 December 2002.

Revised manuscript received 18 December 2002.

Accepted 13 January 2003. 